\title{
VERHANDLUNGEN DER
}

\section{DEUTSCHEN GESELLSCHAFT FÜR INNERE MEDIZIN}

\author{
HERAUSGEGEBEN \\ VON DEM STÄNDIGEN SCHRIFTFÜHRER \\ PROFESSOR DR. B. SCHLEGEL \\ WIESBADEN
}

NEUNUNDSIEBZIGSTER KONGRESS

GEHALTEN ZU WIESBADEN VOM 29. APRIL - 3. MAI 1973

MIT 688 ABBILDUNGEN UND 261 TABELLEN

Enthält u. a. Referate zu folgenden Hauptthemen:

Die zivilisierte Umwelt als krankmachender Faktor, Physiologie und Pathologie des lymphatischen Systems, Grundlagen einer optimalen Arzneimitteltherapie, Aktuelle Leukämieprobleme, Hämatologie, Neuere Erkenntnisse der Virusforschung

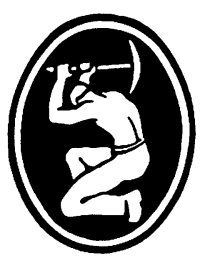

MÜNCHEN

VERLAG VON J. F. BERGMANN 


\section{Eigentum der Universiläls - Pibliothek Münohøn}

Das Werk ist urheberrechtlich geschützt. Die dadurch begründeten Rechte, insbesondere die der Utbersetzung, des Nachdruckes, der Entnahme von Abbildungen, der Funksendung, der Wiedergabe auf photomechanischem oder ähnlichem Wege und der Speicherung in Datenverarbeitungsanlagen bleiben, auch bei nur auszugsweiser Verwertung, vorbehalten.

Bei Vervielfältigungen für gewerbliche Zwecke ist gemäß §54 UrhG eine Vergütung an den Verlag zu zahlen, deren Höhe mit dem Verlag zu vereinbaren ist.

Catalog Card Number 73-19036

Druck von Carl Ritter \& Co. in Wiesbaden

Printed in Germany

(c) by J. F. Bergmann, München 1973 


\section{Inhaltsverzeichnis}

Vorsitzender 1973-1974 . . . . . . . . . . . . . . . . . . . XXIII

Vorstand 1973-1974 . . . . . . . . . . . . . . . . . . . . . . XXIII

Vorstand $1972-1973 \ldots \ldots \ldots \ldots \ldots$ XXIII

Ehrenmitglieder . . . . . . . . . . . . . . . . . XXIII

Verzeichnis der Vorsitzenden seit 1882 . . . . . . . . . . . . . . XXVI

Korrespondierende Mitglieder . . . . . . . . . . . . . . . . . . XXXVII

Diplommitglieder . . . . . . . . . . . . . . . . . . . . . XXVII

Ständiger Schriftfïhrer . . . . . . . . . . . . . . . . XXVII

Kassenfïhrer . . . . . . . . . . . . . . . . . . . . XXXVIII

Mitglieder des Aussehusses 1973-1974 . . . . . . . . . . . . . . . XXVIII

Festvortrag: Die Medizin: eine Natur- oder Sozialwissenschaft? Bedingungen und Gefährdungen des ärztlichen Handelns in der Gegenwartsgesellschaft. Von BAIER, H. (Frankfurt/Main). . . . . . . . . . . . . . . . . . . . . . . . 1

Begriißungsansprache des Vorsitzenden H. Begemann (München) . . . . . . . . . 12

Totenehrung . . . . . . . . . . . . . . . . . . . . . . . 13

Theodor Frerichs-Preis 1973 . . . . . . . . . . . . . . . . . . . . . . . . . 15

E. K.-Frey-Preis $\mathbf{1 9 7 3}$. . . . . . . . . . . . . . . . . . . . . . . . . . . . . . . . . 15

Eröffnungsansprache des Vorsitzenden der Deutschen Gesellschaft für innere Medizin. Von BegemanN, H. (München) . . . . . . . . . . . . . . . . . . . . . . 16

\section{Referate, Vorträge und Aussprachen}

\section{DIE ZIVILISIERTE UMWELT ALS KRANKMACHENDER FAKTOR}

Das circardiane System. Grundlagen der Tagesperiodik und ihrer Bedeutung für angewandte Psychologie und Klinik. Aschoff, J. (Seewiesen-Erling-Andechs) (Referat)

Pathogene Auswirkungen von exogenen Rhythmusstörungen. Rutenfranz, J. (Dortmund) (Referat) .

Chemisch-physikalische Noxen durch Verunreinigung der Atmosphäre. Antweiler, $H$. (Düsseldorf) (Referat)

Aussprache: Herr SchetrLen, G. (Heidelberg) .

Pathogene Faktoren in Lebensmitteln pflanzlicher und tierischer Herkunft. Crener, $H$. (Gießen) (Referat)

Arzneimittel als Krankheitsursache. Kewitz, H. (Berlin) (Referat) Aussprache: Herr ScheTrter, G. (Heidelberg) .

Häufigkeit und Folgen der Einwirkung mutagener und teratogener Substanzen. v. KREYBIG, TH. (Hamburg) (Referat).

Allergie im Zusammenhang mit Faktoren der zivilisierten Umwelt. Banduan, H. J. (München) (Referat)

Soziokulturelle Faktoren und innere Krankheiten. PfLanz, M. (Hannover) (Referat) .

Ausbruchsversuche des Individiums aus seiner zivilisierten Umwelt - Traum, Sucht, Selbstmord. Pohlmerer, H. (Ulm) (Referat)

Medizin-soziologische Konzepte der Krankheitsentstehung. Ferber, Chr. (Bielefeld) (Referat)

1. Rundtischgespräch. Der Mensch als Schädiger und Geschädigter seiner Umwelt: Möglichkeiten der Durchbrechung eines circulus vitiosus. Moderator: BuRHenne, W. E. (Bonn) 


\section{PHYSIOLOGIE UND PATHOLOGIE DES LYMPHATISCHEN SYSTEMS}

Lymphocytenformen: Herkunft und Entwicklungsmöglichkeiten. CoTtıer, H., Hes.s, M. W., Schädeli, J., BürkI, H. (Bern) (Referat) . . . . . . . . . . . . . .

Kinetik der Lymphocyten. Trepel, F. (Ulm) (Referat) . . . . . . . . . . . . . .

Die Regulation des lymphatischen Systems. Brent, L., Davies, A. J. S. (London) (Referat)

Funktionen der Lymphocyten im Rahmen der Immunreaktionen. RAJEwskr, K. (Köln) (Referat)

Die Rolle der Lymphocyten bei der Wahrung der individuellen Integrität. Grundmass, E. (Münster) (Referat) . . . . . . . . . . . . . . . . . . . . . . . . . .

Lymphocyt $=$ Lymphocyt ? Die Bezichung zwischen Lymphocyten und den hämopoetischen Zellsystemen. Fliedner, Th. M. (Ulm) (Referat) . . . . . . . . . .

Einfliusse des lymphatischen Systems auf den Alterungsvorgang. WALFORD, R. L., TitTor, W. (Los Angeles) (Referat)

Lymphocytenkinetik bei lymphatischen Systemerkrankungen (chronische lymphatische Leukämie, Lymphogranulomatose). ScHIck, P. (München) (Referat)

Immunpathologie bei lymphatischen Systemerkrankungen. HuBER, H., HuBER, CH., Michlmayr, G. (Innsbruck) (Referat)

Die Therapie der lymphatischen Systemerkrankungen (Lymphogranulomatose, Lymphound Reticulumzellsarkom). Brunner, K. W. (Bern) (Referat) . . . . . . . . .

Pathomechanismen bei Autoaggressionskrankheiten. YEYeR zun Büschenfelde, K. H. (Mainz) (Referat)

2. Rundtischgespräch. Gezielte Immunstimulierung und Resistenzsteigerung. Moderator : Fischer, H. (Freiburg) .

\section{GRUNDLAGEN EINER OPTIMALEN ARZNEIMITTELTHERAPIE}

Die Feststellung der therapeutischen Breite des Arzneimittels. Herken, H. (Berlin) (Referat) .

Aussprache: Herr Schettler, G. (Heidelberg) .

Die Bedeutung der Pharmakokinetik fiir die Therapie. Dengler, H. J. (Bonn) (Referat) 205

Ursachen von Arzneimittelwechselwirkungen. NETTER, K. J. (Mainz) (Referat) . . . 205

Wirkungsveränderungen von Arzneimitteln durch Induktion und Inhibition fremdstoffabbauender Enzyme. Remuer, H. (Tübingen) (Referat) . . . . . . . . . . . .

Arzneimitteldosierung bei Krankheiten der Eliminationsorgane. Detrli, L. (Basel) (Referat)

Pharmakologische Grundlagen von Stoffwechselstörungen und Arzneimittelunverträglichkeiten. Goedde, W. (Hamburg) (Referat)

Pharmakogenetische Ursachen bei der Manifestation hämatologischer Erkrankungen. Löhr, G. W., Blume, K. G., Arnold, H. (Freiburg i. Br.) (Referat) . . . . . .

Arzneimittelabhängigkeit und -gewöhnung in biochemisch-pharmakologischer Sicht. Herz, A. (München) (Referat) .

Konsequenzen des neuen Arzneimittelgesetzes für die klinische Prïlung. Neuhaus, G. A. (Berlin) (Referat)

\section{AKTUELLE LEUKÄMIPROBLEME}

Eröffnungsansprache der gemeinsamen Sitzung der Deutschen Gesellschaft für Hämatologie und der Deutschen Gesellschaft für innere Medizin. Pribilla, W. (Berlin) . .

Einteilung der Leukämien : ihre Morphologie und Beziehungen zur Prognose. Rastetter, J. (München) (Referat) .

Die klinische Epidemiologie der Leukämien - ein Weg zur Ätiologie. Dörken, H. (Hamburg) (Referat) .

Faktoren der Leukämogenese. SEIdeL, H.-J. (Ulm) (Referat) . . . . . . . . . . . .

Cytokinetik leukämischer Zellen bei akuten Leukämien des Menschen. Killmane, S. A. (Kopenhagen) (Referat).

Friihphasen und Vorstadien der akuten Leukämie. Heinpel, H. (Ulm) (Referat). . .

Strahlenbiologische Grundlagen der Leukämiebehandlung. LAJTha, L. G. (Manchester, England) (Referat) . 
Die pharmakologischen Grundlagen der Behandlung der Leukämien. OвRecht, J. P. (Basel) (Referat) . . . . . . . . . . . . . . . . . . . . . . . . .

Unspezifisehe Basistherapie der Leukämien und ihrer Komplikationen. Brittinger, G. (Essen) (Referat)

Die Therapie der chronisehen lymphatischen Leukämie. ThenL, H. (München) (Referat)

Therapeutisches Vorgehen bei der chronischen myeloischen Leukämie. Hunstein, W. (Heidelberg) (Referat)

3. Rundtischgespräch. Behandlung der akuten Leukämie. Moderator: Gross, R. (Köln)

\section{Hämatologie}

Leicht zu verkennen: Das Hypo- $\gamma$-Myelom. Kolenda, K.-D., Müller, G., Schmidt, K., ToLk, J. (Kiel)

Verminderung der $\beta_{1 \mathrm{E}}$-Globulin-(C4)-Konzentration im Serum bei IgG-Plasmocytom und Makroglobulinämie Waldenström. Augener, W., Cohen, G., König, E., Brittinger, G. (Essen)

Verschiedene Verlaufsformen der Makroglobulinämie Waldenström. BRAUN, H. J., Bruchraus, K.-F., Aly, F. W. (Tübingen)

Monoklonales Kryoglobulin mit antinucleärer Aktivität und S-Kettenfragment bei Morbus Waldenström. Hufnagel, H. D., Schwarz, J. A., Jost, H., Scheurlen, P. G. (Homburg/Saar)

$\mu$-Kettenkrankheit und Hyper- $\gamma$-Globulinämie - eine ungewöhnliche Immunglobulinstörung mit allgemeiner Lymphadenopathie. Wetter, O. (Essen)

Ergebnisse einer Kombinationschemotherapie mit Cytarabin und 6-Thioguanin bei akuter Leukämie. Drings, P., Fritsch, H., v. KaICK, G., Moskwa, G., Sefrin, R. (Heidelberg).

Die Beeinflussung des Verlaufs akuter Leukämien durch Fortschritte in der Chemotherapie. MüLler, K. A., Mainzer, K. (Mainz).

Behandlungsergebnisse bei cytochemisch klassifizierten unreifzelligen Leukosen. Löffler, H., Pralle, H., Lück, R., Fischer, J., Roux, A. (Mainz) . . . . . . .

Indikation und Kontraindikation zur Behandlung akuter Leukämien mit Corticosteroiden. Theoretische Grundlagen. Wilmanss, W., Wilms, K., Müller, D. (Tübingen)

Polyribonucleotidaufnahme menschlicher Leukocyten unter physiologischen und pathophysiologischen Bedingungen. Moser, K., Ganzinger, U., Piller, G., Stacher, A., Rainer, H. (Wien)

Fehlermöglichkeiten bei der Differenzierung von Blutausstrichen aus EDTA-Blut. Hauswaldt, Ch., Schröder, U. (Göttingen) . . . . . . . . . . . . . . . .

Elektronenmikroskopische Veränderungen des Knochenmarks von akuten Leukämien vor und nach Therapie mit Cytosin-Arabinosid. Ruzicka, F., Weigerstorfer, B. (Wien)

Zur praktisch-diagnostischen Bedeutung enzymhistochemischer Untersuchungen an Beck'nkammbiopsiepräparaten. Lorbacher, P., WoHLenberG, H. (Wiesbaden) .

Der NBTT-Test, eine diagnostische Hilfe bei der Differenzierung pathogenetisch unterschiedlicher Leukocyten und febriler Erkrankungen. Douwes, F. R., Hauswaldt, Cir. (Göttingen)

Cytologie und Cytochemie der Friend-Virusleukämiezellen während der Ausdifferenzierung im Vergleich zu menschlichen Leukämiezellen. Knebel, A., Beckmans, H., KLUGE, N. (Hamburg)

Die wechselnde klinische Symptomatik cytochemisch charakterisierter Monocytenleukämien. KLeIN, U. E., UdE, P. (Kiel) . . . . . . . . . . . . . . . . . .

Der direkte bakteriolytische Lysocymnachweis im Blutausstrich bei unreifzelligen Leukusen. Labedzki, L., Dengler, H. J. (Bonn), Lorbacher, P. (Wiesbaden). .

Zur DNA-Synthese leukämischer Leukocyten. Rainer, H., Piller, G., Moser, K., Höcher, P., Stacher, A. (Wien).

Aussprache: Herr Garbrecht, M. (Hamburg) .

Herr Mertelsmann, R. (Hamburg) .

Eine neue Proteinabnormität im Urin von myeloischen Leukämien. Ledderose, G., Trschendorf, F. W., Wilmanns, W., Tischendorf, M. M. (Tübingen) . . . . . 
Der klinische Wert einer routinemäßigen Bestimmung des Vitamin $B_{12}$ im Serum. Preiss, J., Gamm, H., Fischer, J. (Mainz)

Menge, Variabilität und Meßverfahren von Plasma- oder Waschflüssigkeitsresten in Zellkonzentraten. Burck, H.-CHR. (Tübingen)

Leukämieentstehung nach Benzol und Phenylbutazon. Hartwich, G., Lutz, H. (Erlangen-Nürnberg) .

Erkrankungen des Knochenmarks bei Thorotrastträgern. van KAICK, G., LoRExz, D., Drings, I. (Heidelberg)

Die leukämogene Wirkung von Thorotrast. ZACH, ST., ZACH, J. (Köln) .

Lymphknotenveränderungen bei experimenteller Leukämie in Long-Evans-Ratten. Mainzer, K. (Mainz), Bird, C. (Edinburgh) . . . . . . . . . . . . . . . . .

70S-RNS enthaltende Partikel in menschlichen Leukämien. Hehlmann, R., Kufe, D., Baxt, W., Spieglemand, S. (New York, USA)

392

394

396

399

Messenger-RNS und ribosomale RNS-Synthese in Leukämiezellen während der Zellausdifferenzierung. Neth, R., Wiegers, U., Beckmann, H., Gaedicke, G., WinkLER, K. (Hamburg).

Hydrolaseaktivität für N-substituierte Aminoacyl-tRNA während der Zellausdifferenzierung normaler und leukämischer Blutzellen. Nowrath, J., Neth, R., Hersisch, B., WINKLER, K. (Hamburg)

Transfer-Ribonucleinsäure-Methyltransferasen bei verschiedenen Hämoblastosen. Schöch, G., Heller-Schöch, G., Winkler, K., Mertelsuani, R., Garbrecht, M. (Hamburg) .

Klinische Beobachtungen bei präleukämischen Stadien. WildHack, R. (Hamburg)

Zur Frage der Präleukämien. Bömnel, J., Stacher, A. (Wien)

Megakaryocytenpolyploidisierung bei akuter Leukämie und Präleukämie. Quessser, W., Queisser, U., Avsuanv, M., Bruvner, G., Hempel, H., Hoelzer, D. (Ulm)

Klinische und cytogenetische Untersuchungen bei präleukämischen Zuständen. BAUkE, J., Hoerler, H., Giencier, S., Heimpel, H. (Ulm).

406

408

410

413

415

416

419

Beziehungen zwischen Chromosomenbefund und Prognose in akuten myeloischen Leukämien. Hossfeld, D. K., SAkurai, M., Sandberg, A. A. (Essen-Buffalo) . .

Chromosomale Veränderung bei einem Fall einer Erythroleukämie. Reusch, D., Pöttgen, W. (Düsseldorf)

Granulocytenkinetik bei Neutropenien. Fischer, M., Holtz, G., Mrtrou, P. S. (Frankfurt/Main).

Lymphocytentransformation und Immunglobuline bei Kindern mit akuter lymphatischer Leukämie und malignen Tumoren. Pappas, A., Wahlen, W., Kausch, O., Scheurlen, P. G., Mayer, J. B. (Homburg/Saar) .

Anreicherung von Erythroblasten aus menschlichem Knochenmark im Albumingradienten. Trgaes, F.-J., Waller, H. D. (Tübingen).

Untersuchungen zur Erythropoese bei erythroleukämischen Zellkulturen. OsterTaA, W., Kluge, N., Melderis, H., Streinheider, G., Gaedicke, G. (Göttingen), Dube, S. (Hamburg-Eppendorf)

Cytophotometrisch-autoradiographische Untersuchungen an lymphoiden Zellen des menschlichen Knochenmarks. Kempgens, U., MaYer, M., Müller, U., Queisser, W. (Heidelberg)

Synthese von menschlichem Hämoglobin in Polycythaemia vera-Zellkulturen. MeldeRIS, H., Dube, S. K., Ostertag, W. (Göttingen)

Polycythaemia vera: Neoplastische Transformation von Knochenmarkszellen in vitro. Kluge, N. (Göttingen); Knebel, A., Beckmann, H. (Hamburg)

Untersuchungen der Erythropoetinaktivität und zur Frage eines Erythropoetininhibitors in Plasmakonzentraten von Patienten mit Polycythaemia vera. Essers, U., Haddy, T., Brunner, R. (Aachen)

Kurz- und Langzeitadaptationsmechanismen der Erythropoese nach Aderlaß bei Polyglobulien unterschiedlicher Ätiologie. Bock, E., KubANeK, B., Kleeberg, U., Bock, O., Lange, C. (Ulm).

Das Verhalten des Erythropoetinspiegels im Serum bei verschiedenen Nierenerkrankungen. Heilmans, E. (Münster) 
Beeinflussung der Erythropoese-hemmenden Wirkung von Urämikerserum durch Dialyse. Uhu, N., Hunstern, W., Rehn, K. (Heidelberg) . . . . . . . . . . .

Untersuchungen zur Beurteilung der Eisenvorräte bei terminaler Niereninsuffizienz. Kramer, P., Hauswaldt, C., Lankisch, P. G., Schrader, C., OtTen, E., Köthe, E., Scheler, F. (Göttingen).

Die osmotische Resistenz der Erythrocyten bei chronischer Niereninsuffizienz. Daniels, V., Bundschu, H. D., DürR, F. (Tübingen) .

Reduziertes Glutathion (GSH) in Erythrocyten bei myeloproliferativen Erkrankungen. Be nöhr, H. Chr., Tigges, F. J., Waller, H. D. (Tübingen). . . . . . . . . .

Einfluß von Flavin-Adenin-Dinucleotid (FAD) auf die Aktivität der Glutathionreduktase menschlicher Erythrocyten, Leukocyten und Thrombocyten. BexöHR, H. Chr., Dreher, R., Neunhöffer, J., Waller, H. D. (Tübingen) . . . . . .

Der erythrocytäre 2,3-Diphosphoglyceratgehalt bei Patienten mit angeborenen und erworbenen Herzfehlern prä- und postoperativ. Mertens, H. M., Klapdor, A., Bircks, W., KuHN, H., Kübler, W. (Düsseldorf)

Charakterisierung immunhämolytischer Anämien mit negativem Antiglobulintest. Fischer, J. Th., Garratty, G., Petz, L. D. (Düsseldorf-San Francisco). . . . . .

Úber die Makrocytose bei Lebercirrhose und ihre Normalisierung unter der Therapie. Becker, HJ., Mosawr, N. (Frankfurt/Main) . . . . . . . . . . . . . . . . .

Ferrokinetische Untersuchungen bei Kranken mit erythropoetischer Knochenmarkinsuffizienz. Glaubitt, D., Schneider, J., Gerhartz, H. (Berlin) . . . . . . .

Verlaufsbeobachtung einer Fanconi-Anämie bei einem Erwachsenen. ScHroeder, T. M., Drings, P. (Heidelberg).

Verlauf und Prognose der Panmyelopathie unter modernen Therapiebedingungen. Heinipel, H., Bock, E., Reisicke, Ch. (Ulm).

Thrombocytenmarkierung mit ${ }^{75} \mathrm{SE}$-Selenmethionin beim hämatologisch Gesunden. Müller, U., Kulinna, J., Hebestreit, H.-P., Kempgens, U., Queisser, W. (Nannheim-Heidelberg).

Untersuchungen zur Pathogenese der alkoholischen Thrombocytendepression mittels radioaktiver Blutplättchenmarkierung. Heck, J. (Wuppertal-Barmen) . . . . .

464

466

Nachweis von Thymidinphosphorylase und Thymidinkinase in normalen menschlichen Blutplättchen. SchNeIder, W. H. G. (Homburg/Saar)

Einfluß von cyclischem ANP auf den Glucosestoffwechsel in menschlichen Blutplättchen. Schneider, W. H. G., Villar-Palasi, C., Larner, J. (Homburg/SaarCharlottesville/USA)

Atypische kongenitale dysery thropoetische Anämie mit Thrombocytopenie. KöNIG, E., Osieka, R., Brittinger, G. (Essen)

Zur Frage der T- und B-Zellennatur der Blutlymphocyten bei Morbus Hodgkin. Cohnen, G., König, E., Augener, W., Brittingler, G. (Essen); Dovglas, S. D. (New York/USA)

Lymphocyteneigenschaften. Gallieier, W. M., Pfeiffer, R., Brun'ssch, U., Bestek, U., ScrmidT, C. G. (Essen) . . . . . . . . . . . . . . . . . . . . . . . .

Knochenmarkbiopsie bei Morbus Hodgkin. Dexnhard', H. H., Hilr, K. (Mainz) .

Die Knochenmarkszintigraphie bei Morbus Hodgkin. Gamm, H., Fischer, J., Preiss, J., Wolf, R. (Mainz) .

Die Wertigkeit radiologischer Maßnahmen zur Stadieneinteilung maligner Lymphome. Erbe, W., Wiebe, V., Freisenhauses, H. D. (Hamburg) . . . . . . . . . .

Milzbefall bei Morbus Hodgkin: Ergebnisse der Splenektomie in 80 Fällen. Fischer, J., Roux, A., Brünser, H., Hill, K., Melchert, R., Kotulla, W., Dennhardt, H. H., Fahimian, A. (Mainz)

Milzfunktion bei Morbus Hodgkin. Hornung, G., Hırche, H., Höfrkex, K., Becker, G., Deckner, K., Schmidt, C. G. (Essen) .

Vergleichende sonographische und lymphographische Untersuchung der retroperitonealen Lymphknoten bei malignen Lymphomen. Iutz, H., Stury, G., HarTwich, G. (Erlangen-Nürnberg) . . . . . . . . . . . . . . . . . . . . .

Quantitative Immunglobulinbestimmung ( $\operatorname{IgA}, \operatorname{IgG}, \operatorname{IgM})$ bei Lymphogranulomatose. Sailer, D., Lutz, H., Hartwich, G. (Erlangen-Nürnberg)

Chronisch-lymphatische Leukämien und humorale Immunität. Pauliscir, R. (Berlin) 
Basenanalysen, Oligonucleotidfrequenzen und Markierungskinetik hochmolekularer Ribonucleinsäuren aus menschlichen Leukosen und Lymphomen. SeEber, S., SchmidT, C. G. (Essen)

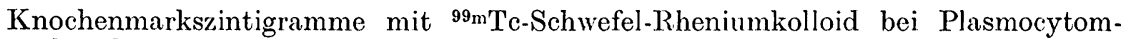
kranken. Schneider, J., Glaubit't, D., Gerhartz, H. (Berlin) . . . . . . . .

Anreicherungsmechanismus von Gallium-67 in normalen und maligne entarteten Zellen. Deckner, K., Becker, G., Langowski, U., Hornung, G., Schmidt, G., Schyidt, C. G. (Essen)

Phasenkontrastoptische Untersuchungen bei Speicherkrankheiten. ZACH, ST., ZACH, J. (Köln)

Beurteilung von Progression und Remission bei der chronischen lymphatischen Leukämie (CLL). Westerhauses, M. (Freiburg i. Br.)

Thrombocytenkinetik bei lymphoproliferativen Erkrankungen. GeHrMarn, G. (Wuppertal) . . . . . . . . . . . . . . . . . . . .

Ergebnisse bei Langzeitbehandlung chronischer Lymphadenosen mit extrakorporaler Blutbestrahlung. FröHLICH, D., Bock, O. (Ulm)

Therapie chronischer Leukämien durch Leukopherese mittels eines Zellseparators. Stacher, A., Höcker, P., Gobets, M. A. (Wien)

Zum Einfluß der extrakorporalen Blutbestrahlung auf Klinik und Lymphocytenfunktion bei chronischer lymphatischer Leukämie. HoNetz, N., Frischaur, H., MadL, W., Mittermayer, K., Neumann, E. (Wien)

In-vitro-Untersuchungen über den Glykogenstoffwechsel von Blutlymphocyten. DoEnecke, C. (Homburg/Saar) . . . . . . . . . . . . . . . . . . .

Biochemische Untersuchungen des Glykogenstoffwechsels an menschlichen Blutlymphocyten. Seiler, D., Kelleter, R. (Heidelberg) . . . . . . . . . . . .

Glykogenstoffwechsel in Blutlymphocyten von Patienten mit chronisch-lymphatischer Leukämie. Kelleter, R., Seiler, D., Drisgs, P. (Heidelberg) . . . . . . . .

Elektronenmikroskopisch-cytochemische Untersuchungen über den Lysosomengehalt in Mitogen-stimulierten Lymphocy ten von Patienten mit chronischer lymphatischer Leukämie. Cohnen, G., König, E., Brit'inger, G. (Essen); Douglas, S. D. (New York)

Rosettenformation bei Gesunden und bei Patienten mit chronisch-lymphatischer Leukämie. Fink, U., Strebel, J., Weig, J., Sepp, F., Rastetter, J., MullerBerat, N. (München-Kopenhagen) . . . . . . . . . . . . . . . . . .

Anreicherung normaler Lymphocyten in der Lymphe von Patienten mit chronischer, lymphatischer Leukämie. Brener, K., Schreml, W., Flad, H. D. (Ulm) . . . .

Gestörte B-Zellrezirkulation bei chronischer Lymphadenose. Huber, Ch., Huber, H., Menne, H. D., Asamer, H., Flad, H. D., Bremer, K. (Innsbruck-Ulm) . . . .

DNS-gesteuerte Nucleinsäure-Polymerasen in normalen und pathologischen menschlichen Leukocyten: Differenzierung, Charakterisierung und Aufreinigung der DNSPolymerasen I, II und der RNS-Polymerasen A, B und ihre in vitro-Beeinflussung durch Cytostatika. Mertelsmand, R., Garbrecht, M. (Hamburg-Eppendorf) . .

DNS-gesteuerte Nucleinsäure-Polymerasen in normalen und pathologischen menschlichen Leukocyten: erhöhte spezifische Aktivitäten und unterschiedliche Kinetik der RNS-Polymerase B in Kernen pathologischer Zellen. Garbrecht, M., MertelsMANN, R. (Hamburg) .

\section{NEUERE ERKENNTNISSE DER VIRUSFORSCHUNG}

Slow-Virus-Infektionen. TER MEuLen, V. (Würzburg) (Referat) .

Persistierende Virusinfektionen. Waterson, A. P. (London) (Referat) . . . . . . 557

Viruslatenz und Aktivierung. zUR HAUSEN, H. (Erlangen-Nürnberg) (Referat) . . . 562

Virusinduziertes Fieber und seine Rolle bei der Infektabwehr. SIEgert, R. (Marburg a. d. Lahn) (Referat)

Therapeutische Möglichkeiten bei Viruskrankheiten. EGGERs, H. J. (Gießen) (Referat)

4. Rundtischgespräch. Zur Virusgenese menschlicher Tumoren. Moderator: Vogt, P. K. (Los Angeles) 


\section{Immunologie}

Oberflächenimmunglobulin aus Thymuszellen der Maus. RiethmülleR, G., Rieber, E. P., Müller, T., Rietilmüller, D., HadaM, M. (Tübingen) . . . . . . . . .

Cyclisches AMP in normalen und PHA-stimulierten Lymphocyten. Schwarzmerer, J. D., LUJF, A. (Wien)

Einfluß eines Thymushormons auf die Immunantwort der hypophysektomierten und thymektomierten Ratte. Schwarz, J. A., CoMsA, J., Ziegler, P. (Homburg/Saar)

Beeinflussung der Antikörperspezifität durch vorherige Toleranzinduktion und Thymektomie. Schwarz, J. A., Harbauer, G., Neu, H., Schedrlen, P. G. (Homburg/Saar)

Die Peroxydasereaktion während der in vitro-Differenzierung von Leukocyten zu lymphoiden Zellen. voN HeYdeN, H. W. (Tübingen) . . . . . . . . . . . . .

Abstoßung und Schutz vor Abstoßung von Transplantaten durch humorale Antikörper. Baldamus, C. A. (Hannover)

Untersuchungen zur Pathogenese des partiellen neuromuskulären Blocks bei experimenteller Myasthenia gravis. KaLdEx, J. R. (Hannover) . . . . . . . . . . .

Häufigkeit und Vorkommen lymphocytotoxischer Antikörper und Autoantikörper in einem unausgewählten und einem ausgewählten Krankengut. Malchow, H., Klingeliöfer, H. L., Rau, B., Tücke, M., Himmelmany, G. (Marburg) . . . .

Die Aktivität von Monocytenreceptoren für $\operatorname{IgG}$ und $\mathrm{C} 3$ bei Patienten mit Sarkoidose. Schmidt, M., Sodomann, C.-P., Douglas, S. D. (Marburg-New York) . . . . .

Nachweis von Autoantikörpern nach Organtransplantation. Istorp, H. W., KrUpke, H. J., Losse, H. (Münster) . . . . . . . . . . . . . . . . . . . . . . . .

Goodpasture-Syndrom nach Kohlenwasserstoffexposition. ReICheL, W., Schatz, R., Scheler, F. (Göttingen)

Lymphocytentransformation durch Phytohämagglutinin $\mathrm{P}$ bei Patienten mit Multipler Sklerose. Hierholzer, E., Kuwert, E. (Essen) . . . . . . . . . . . . . . .

Serum-Immunglobulinspiegel bei akuter und chronischer ischämischer Coronargefäßerkrankung. Gotwwik, M. G. (Boston, Mass.) . . . . . . . . . . . . . . . .

Der Einfluß von Prednisolon auf die PHA-induzierte Euchromatisierung in menschlichen Lymphocyten. Drings, P., Sonvemann, E. (Heidelberg) . . . . . . . .

Hemmung der Antikörperbildung präsensibilisierter Organismen durch Cyclophosphamid. Herrlinger, J. D., Müller-Ruchitoltz, W. (Kiel) . . . . . . . . .

Untersuchungen zur immunsuppressiven Wirkung von D-Penicillamin. JUxGe, U., Hauswaldt, Сh., Perings, E. (Göttingen) . . . . . . . . . . . . . . . . .

Immunsuppression durch Antiphlogistika. Wirth, W., Müller, U. St., Oschinski, G. M., Oschinskr, H. M. (Münster) .

Bestehen Korrelationen zwischen hämatologischen Befunden und Immunoglobulinen bei Azatlioprin-behandelten Autoimmunkrankheiten? Pelm, K., Hunstein, W., Uhl, N., Scheiter, B. (Heidelberg)

Steigerung der Aktivität von Peritonealmakrophagen der Maus durch Levamisole. Scmllze, H. J., RaktTig, HJ. (Berlin) . . . . . . . . . . . . . . . . . . .

Tmmuno Responses in Elderly Cuti-Negative Subjects and the Effect of Levamisole. Verifaegen, H., de Cree, J., Verbruggen, F., Hoebeke, J., de Brabander, M., Brugmans, J. (Antwerpen, Beerse/Belg.)

Serologische und fluorescenzhistologische Australia-Antigenbefunde im Verlauf der akuten Australia-Antigen-positiven Virushepatitis. Müllen, R., Makss, J., Wirtwer, W., Zetdler, U., Deicher, H. (Hannover) . . . . . . . . . . . .

Radioimmunassay zum Nachweis von AU-(SH)-AG. (Prospektive Studie zur Hepatitis nach Herzoperationen). LehmanN, H., SchlaAK, M. (Kiel)

Zur Frage einer zellgebundenen Präsenz von Au-(SH)-Ag im peripheren Blut. Schlatak, M., Lemmann, H. (Kiel)

Aussprache: Herr Schoppe, W.-D. (Düsseldorf), Herr Bandilla, K. (Wiesbaden)

Immunglobuline bei der akuten Hepatitis. Stiess, G., Berthold, H. (Freiburg). . .

Die Hepatitis - Eine Virus-induzierte Autoimmunkrankheit. Berthold, H. (Freiburg)

Celluläre Immunreaktionen gegenüber dem Hepatitis-assoziierten Antigen (HAA) und homologem leberspezifischem Antigen (HLP) bei akuten HAA-positiven Hepatitiden. Krolle, J., Meyer zum Büschenfelde, K. H., Friedrichs, N., Bolte, J. P. (Mainz) 
Australia-Antigen, HL-A-Antigene und Lymphocyten-Auto-Antikörper bei chronisch aggressiver und chronisch persistierender Hepatitis. Bertrans, J., ReIs, H. E., Kuwert, E., Selmair, H. (Essen-Kassel)

HL-A-Antigenverteilung bei Lebererkrankungen. Freudenberg, J., Erdmann, K., Meyer zun Büschenfelde, K.-H., Förster, Edith, Berger, J. (Mainz)

Nachweis und Bedeutung von Antikörpern gegen homologes Gefäßendothel bei Leberund anderen Krankheiten. Berg, P. A., Brandt, H., Mürker, A. (Tübingen) . .

Antikörpermuster bei autoimmunen Hepatitiden: Klinische Signifikanz und differentialdiagnostische Bedeutung. BerG, P. A., Märker, A., Traunecker, U. (Tübingen-Hamburg)

Untersuchungen des Serumkomplements bei entzündlichen Lebererkrankungen. Meyer zum Büschenfelde, K. H., Ringelmany, R., Opferkuch, W., Heimer, D., EckhardT, R. (Mainz)

Immunologische und elektronenmikroskopische Befunde nach Bildung von Leberautoantikörpern. Intorp, H. W., Stohlmasx, J., Gruber, H., von Bassewitz, D. B. (Münster) .

Versuche zur Induktion einer Hepatitis durch Sensibilisierung mit autologen Leberpräparaten. Götz, H., Schlich', I. (Berlin) .

Zur Isolierung vitaler Hepatocyten für immunologische in vitro-Untersuchungen. Hopf, U., Meyer zum Büschenfelde, K. H., Freudenberg, J. (Mainz) . . . .

\section{Nephrologie}

Zum Verhalten der Nierendurchblutung nach Hydrochlorothiacid. Reploh, H. D., Bender, F., Gradaus, D., Siepmane, A. (Münster)

Forcierte Diurese und Harnstoffausscheidung bei fortgeschrittener Niereninsuffizienz. Quirin, H., Schaeffer, G., Lindenmaier, K., Baumann, G., Kluthe, R. (Freiburg)

Postdiuretisches Verhalten der Harnsäureclearance nach intravenöser Furosemidanwendung. Rieger, J., Fernandez, E., Girndt, J., Köthe, E., Scheler, F. (Göttingen) .

Untersuchungen zur Wirkung von unterschiedlichen Pharmaka auf die Membranen des proximalen Tubulus der menschlichen Niere. Mackenrotd, G., Schröder, H. M., Mondorf, A. W., Scherberich, J. E., Schoeppe, W. (Frankfurt/Main) .

Vergleichende Untersuchungen zur Nephrotoxicität von Aminoglykosiden: Gentamycin und Tobramycin. SAck, K., Wilhely, J. (Lübeck) . . . . . . . . . . . . . .

Zur Stoffwechselwirkung der Vitamin- $\mathrm{D}_{3}$-Hormone: in vitro-Effekt des 25-Hydroxycholecalciferols (25-HCC) auf die Gluconeogenese der Nierenrinde der Ratte aus Pyruvat. Henning, H. V., Gloth, R., Scimbler, F. (Göttingen) . . . . . . . .

Die Wirkung von Lespenephryl bei chronischer Niereninsuffizienz. Graben, N., Bock, K. D. (Essen)

Flammenlose Atomabsorption zur Spurenelementanalyse in biologischen Materialien Aluminiumbestimmungen nach Aludrox-Gabe bei Niereninsuffizienz. FucHs, C., Brasche, M., Donath, U., Henning, H. V., Knoll, D., Nordbeck, H., Paschen, K., Quellhorst, E., Scheler, F. (Göttingen)

Frühdistale Natriumkonzentration und glomeruläre Filtrationsrate beim experimentellen, hämoglobinurischen Nierenversagen der Ratte. Greven, J., Greven, U. (Aachen)

Experimentelle Untersuchungen über die Bedeutung der intravasalen Gerinnung für die Pathogenese der Schockniere. Schuster, H.-P., Mammen, E. F., Iong, M., BlaIR, J. (Mainz-Detroit) .

Immunologischer Nachweis von Membranproteinen des proximalen Tubulus als Parameter für die akute Abstoßungsreaktion nach allogener Nierentransplantation beim Menschen. Moxdorf, A. W., Carpenter, C. B., Scherberich, J. E., Merrill, J. P. (Frankfurt/Main-Boston/Mass.)

Nachweis von Nierengewebsbestandteilen im Urin bei verschiedenen Nierenerkrankungen. Boesken, W. H., Kopf, K., Schollmeyer, P. (Freiburg) . . . . . . .

Zur Säureausscheidung bei Markschwammniere. Werngard, D., Schulze, G., Müller, H., Kutthe, R. (Freiburg) 
Hyperphosphatidämie und Hypercoagulabilität beim nephrotischen Syndrom. JIPP, P., Arkenau, C., Ravens, K. G., Bruhns, H. D. (Kiel) . . . . . . . . . . . . .

Ein Vergleich röntgenologischer und histologischer Veränderungen bei 103 Patienten mit renaler Osteopathie. Hauswaldt, Ch., Wolf, G. (Göttingen) . . . . . . .

Konservative und operative Therapie des Goodpasture-Syndroms. Fassbinder, W., Reitinger, W., Hügel, E., Koch, K. M., Lange, H. P., Malluche, H. H., SCHRÖDER, H. M. (Frankfurt/Main)

Veränderungen an der quergestreiften Muskulatur bei experimenteller Urämie. Matthews, C., Ritz, E., Bundschu, H. D., Hasselbach, W. (München) . . . .

Auswirkungen der Urämie auf die neuronale Aufnahme und Freisetzung von Noradrenalin. Hevendehl, G., Hennemann, H., Heidland, A. (Würzburg) . . . .

Untersuchungen zum Einfluß der Urämie auf die Glucuronidierung von Arzneimitteln in Rattenlebermikrosomen. Leber, H. W., Gleumes, A., Schütterle, G. (Gießen)

Über das Verhalten von Enzymaktivitäten des Harnstoffcyclus und über den Aminosäurestoffwechsel in der Leber bei akuter Urämie. Hoppe-Seyler, G., Scholdmeyer, P., Mater, K. P., Talke, H., Gerok, W. (Freiburg)

Einfluß der Urämie auf die Nährstoffausnützung. Kassler, G., Kasper, H., Grimuel, H., Bongartz, S., Hotz, G. (Würzburg)

Umsatz von ${ }^{131} \mathrm{~J}$-Transferrin bei eiweißarm ernährten Patienten mit fortgeschrittener, chronischer Niereninsuffizienz. Müller, H., Roth, K., Quirin, H., Kleine, N., Kluthe, R. (Freiburg)

Statistische Untersuchungen zur Prognose chronisch niereninsuffizienter Patienten unter streng eiweißarmer selektiver Proteindiät (sog. Kartoffel-Eidiät). Oschslex, D., Quirin, H., Jesdinsky, H. J., Kluthe, R. (Freiburg).

Der Einfluß der chronisch intermittierenden Hämodialyse auf die Lymphocytenstimulierbarkeit durch PHA bei Patienten mit terminaler Niereninsuffizienz. R.EIs, H. E., HeImsoth, V. H. (Essen) .

Die Lactat- und Pyruvatkonzentration bei chronisch dialysierten Patienten in $\mathrm{Ab}$ hängigkeit vom Ausmaß der Anämie. Lange, H., Bode, J. Ch., Seybold, D., Janssen, J., Thüroff, J., Tücke, M. (Marburg) .

Verhalten der Skelethistologie bei urämischer Osteodystrophie nach Erhöhung der Dialysatcalciumkonzentration auf 3,75 mval/1. MALLUCHE, H. H., RITz, E., Koch, K. M., Krempien, B., Schoeppe, W. (Heidelberg) . . . . . . . . . . . . . .

Hypophysen-Nebennierenrindenregulation bei Patienten mit chronischer Niereninsuffizienz unter Dauerhämodialyse. Hrubesch, M., Wagner, H., Wenning, N., Adams, M., Stürmer, H., Böckel, K., Grothe, G., Loew, H., Wessels, F., Hauss, W. H. (Münster)

Untersuchungen zum Testosteronspiegel im Plasma männlicher Patienten unter chronischer Hämodialysebehandlung. Heinrichs, H. R., Milde, K., Junkers, K., Heinze, V., Burmeister, P. (Freiburg) .

Beziehungen zwischen EKG und intra-extracellulärer Elektrolytkonzentration während Hämodialyse. Zumkley, H., WADYsski, A. (Münster) . . . . . . . . . .

Über den Wert der Hämodialysetherapie der hypercalcämischen Krise bei primärem Hyperparathyreoidismus. Loww, H., Wagner, H. (Münster) . . . . . . . . .

Zur Therapie der akuten intermittierenden Porphyrie. Heгmsoth, V. H., Hocevar, V., Graffe, Chr. (Essen)

Hämolyse und akutes Nierenversagen. Heinsoth, V. H., Lubold', W., Bоск, K. D. (Essen)

Erfahrungen mit dem Tenckhoff-Katheter bei der Peritonealdialyse von Patienten mit terminaler Niereninsuffizienz. Lankisch, P. G., Fernandez-Redo, E., Girndt, J., Kramer, P., Quellhorst, Q., Tönnis, H. J., Scheler, F. (Göttingen-Kassel). .

Peritonealdialyse bei Thyroxinvergiftungen? Bischof, W., Bohner, J., WaHL, R., Kallee, E. (Tübingen) . . . . . . . . . . . . . . . . . . . . . . . . . .

Pharmakokinetik von Furosemid unter Hämodialyse. Siemensen, H. C., Augustre, H. J., Preugschat, D., Schlamp, R. (Hamburg). . . . . . . . . . . . . . .

Das Renin-Angiotensinsystem bei persistierender orthostatischer Hypotonie nach Guanaclin. Wende, W., Ochs, H. G. (Aachen) 
Plasma-Reninkonzentration während einer durch Pneumencephalographie induzierten Hypokaliämie. Krause, D. K., Kaufmann, W. (Köln); Hayduk, K., Heckl, R. (Tübingen)

Plasmarenin und Plasmaaldosteron nach Nierenallotransplantation. BeckeRHoff, R., Uhlschmid, G., Vetter, W., Armbruster, H., Siegenthaler, W. (Zürich) . .

Zur Rolle des Aldosteron bei chronischer Niereninsuffizienz. KraMer, H. J., SRour, M., Bourdy, H., KRück, F. (Homburg/Saar)

Plasmaaldosteron und Plasma-Reninaktivität unter Hämodialyse. Vetrer, W., Zaruba, K., Armbruster, H., Begkerhoff, R., Strrebel, U., Siegenthaler, W. (Zürich)

Reninaktivität im Nierenvenenblut und ihre Stimulierbarkeit durch verschiedene Pharmaka. Klumpp, F., Klaus, D., Rössler, R., Sadowski, P. (Tübingen) . .

Hochdosierte Spironalactonetherapie bei Patienten mit ,essentieller" Hypertonie und niedrigem Plasmarenin. Distler, A., Keim, H. J., Lommer, D., PhilipP, Th., Philippi, A., Walter, U., WolfF, H. P.

Vergleichende Untersuchungen des Blutdrucks, der körperlichen Beschwerden und der aktuellen Stimmungslage unter Behandlung mit Clonidin und $\alpha$-Methyldopa. Anlauf, M., Hoersen, H., Hampel, R., Merguet, P. (Essen-Freiburg) . . . .

Die Behandlung der malignen Hypertension mit permanenter Carotissinusnervstimulation. Both, A., Reidemeister, J.-Chr., Höfer, I., Kreuzer, H., Kuhs, H. (Düsseldorf)

Carotis-Sinusnervenstimulation zur Beeinflussung maligner Hypertonien. WAGNER, J., Wilbrandt, R., Kreutzberg, B., Olnhoff, U. (Bonn-Venusberg) . . . . . .

Blutdruckelemetrische Untersuchungen zum Vergleich von Basis- und Entspannungsblutdruck bei Hochdruckkranken. Krönig, B., Moergel, K., JakoB, H., GraULICH, M., JAHNECKE, J. (Mainz)

Kreislaufreflexe bei primärem Aldosteronismus. Philipp, Th., Just, H. J., PHILIPPI, A., Distler, A. (Mainz)

Untersuchungen zur Regulation des Blutvolumens in Orthostase bei Gesunden und Patienten mit arterieller Hypertonie. Molzahn, M., Drssmann, Th., Halrm, S., Lohmann, F. W. (Berlin) .

Gesteigerter Flüssigkeitsumsatz bei einseitiger Nierenarterienstenose des Menschen. Kramer, P., Frisch, G., Köthe, E., Scheler, F. (Göttingen) . . . . . . . . . .

Bestimmung der intrarenalen Hämodynamik bei Patienten mit Nierenarterienstenose. Brech, W. J., Nobbe, F., Rudofsky, G., Franz, H. E. (Ulm) . . . . . . .

Indikation zur Uninephrektomie bei Hochdruck und pyelonephritischer Schrumpfniere. Wigger, W., Girndt, J., Lowitz, H. D., Werner, G., Scheler, F., Grabner, F., Truss, F. (Göttingen)

Der Einfluß adrenerger Pharmaka auf die renale Hämodynamik und Ausscheidungsfunktion. Meurer, K. A., Krause, D. K., Kaufmann, W. (Köln) . . . . . . .

Untersuchungen zur Bedeutung des Natrium- und Kaliumhaushaltes für die Genese der Hypertonic bei Niereninsuffizienz. Dieker, P., LmmberG, P., Schmid, E., Stockert, V., ZimmermanN, H.-D. (Gießen)

Glucosetoleranz und Insulinsekretion bei verschiedenen tierexperimentellen Hypertonieformen. Zierden, E., Wessels, F., Wagner, H., Hauss, W. H. (Münster)

Störung des Katecholaminstoffwechsels bei asympathicotoner Hypotonie. Werner, U. (Essen)

Die Aktivität des sympathoadrenalen Systems bei Patienten mit essentieller Hypertonie. Lohnann, F. W., Dissmann, Th., Gotzen, R., Molzahn, M., Schroeder, G. (Berlin) . . . . . . . . . . . . . . . . . . . .

Nierenarterienstenose und Phäochromocytom. Weiss, M., Müller, H., KröPelin, H., Kluthe, R. (Freiburg)

Die biologische Bestimmung von Katecholaminen im Urin als Screening-Methode zum Nachweis von Phäochromocytomen - unter besonderer Berücksichtigung einer medikamentösen Beeinflussung des Katecholaminstoffwechsels. Ebel, H., Classen, H.-G., Marqardt, P., Pieper, K.-H. (Freiburg) . . . . . . . . . . . . . . .

Zur fluorometrischen Bestimmung von Plasmakatecholaminen. MäUrer, W., Grafflage, B., Kübler, W., KuhN, H., Seipel, L. (Düsseldorf) 


\section{Gastroenterologie}

Auskleidung der distalen Speiseröhre mit Cylinderepithel (Barrett-Syndrom). Wienbeck, M., Heitmann, P., Dombrowski, H., Martini, G. A. (Marburg) . . . . .

Beziehungen zwischen der Schleimhautmorphologie, der Gipfelsekretion (PAO) und dem Serum-Gastrinspiegel bei Patienten mit Hyper-, Normo-, Hypo- und Achlorhydrie. Miederer, S. E., Stadelmann, O., Kaess, H., Elster, K. (Bonn-Heidelberg-Bayreuth)

Serum-Gastrinspiegel und Magensekretion nach Magenteilresektion und Gastrektomie. Fritsch, W. P., Müller, J., Rick, W., Hausamen, T.-U. (Düsseldorf) . . . . .

Zur Ursache der schädigenden Wirkung von Acetylsalycilsäure und Phenylbutazon auf die Magenschleimhaut. HAHN, K. J. (Heidelberg)

Untersuchungen zur Methode der endogastralen Magensafttitration mit einem Intestinalsender. UNGer, W., Kaess, H. (Heidelberg)

Die Wirkung von intragastrischem Calcium auf die Magensäuresekretion beim Menschen. HolterrüLler, K. H., Go, V. L. W. (Rochester/USA) . . . . . . . . .

Medikamentöse Vagotomie durch akute Hypermagnesiämie? Strauch, M., Lux, G., Lux, E., OttenJann, R. (München-Neuperlach) . . . . . . . . . . . . . . .

Orale Antibioticatherapie bei magenresezierten Patienten. Lode, H., Frisch, D., Naumans, P. (Berlin-Düsseldorf)

Magenlymphome - diagnostische und therapeutische Probleme. Rösch, W., HaRTWICH, G. (Erlangen-Nürnberg)

Vergleichende Untersuchungen über die Wirkung von Pankreasglucagon und Secretin auf die Motilität des proximalen und distalen Magen-Darmtraktes des Menschen. PAUL, F. (Hannover).

Vergleichende Untersuchungen zur klinischen Wertigkeit von Bilanz-, Toleranz- und segmentalen Perfusionsmethoden in der Dünndarmdiagnostik. Menge, H., GottesBüren, H., Bloch, R., Lorenz-Meyer, H., Riecken, E. O. (Marburg) . . . . .

Die Wirkung von Pentagastrin und Glucagon auf die Wasser-, Elektrolyt- und Glucoseresorption im menschlichen Jejunum. Ewe, K., Laubenthal, G., Hoditz, U. (Mainz)

Funktionsstörungen des Ileums und Zeichen einer bakteriellen Besiedlung des Dünndarms bei der Enteritis regionalis (Morbus Crohn). Fromm, H. (Hannover) . . .

Die Bedeutung hemmender Nerven für die Colonmotilität. Wienbeck, M. (Marburg)

Nachweis einer charakteristischen Proteinfraktion im Serum von Patienten mit Morbus Crohn mittels Polyacrylamidelektrophorese. Förster, E., Meyer zum BüschenFELde, K.-H., Bierbach, H., Holldorf, A. W. (Mainz-Bochum)

Morphologische und biochemische Veränderungen der Dünndarmschleimhaut beim Blinisack-Syndrom. Bloch, R., Menge, H., Lorenz-Meyer, H., Rrecken, E. O. (Marburg)

Stimulierung des exokrinen Pankreas durch intraduodenal verabreichtes Albumin und ein Albuminhydrolysat beim Menschen. Dollinger, H. C., Goebell, H. (Ulm)

Bestimmung von Trypsin und Chymotrypsin im Stuhl als Suchtest für eine exokrine Pankreasinsuffizienz. Schneider, R., DürR, H. K., Bode, J. Ch. (Marburg) . . .

Exkretorische Pankreasfunktion der Ratte: Hemmung durch hohe Dosen CCKPankreozymin und Narkose. Hotz, J., Neumann, K., Zoller, A., Ziegler, R., GOEBELL, H. (Ulm-Marburg)

Pankreasdiagnostik mit der Ultraschall-Schnittbildmethode. ReTrenmaier, G. (Erlangen)

Aussprache: Herr Phlippen, R. (Köln)

Untersuchungen zum Stoffwechsel der Serumanalyse. NoRd, H. J., WeIs, H. J., Cölle, H. (Mainz)

Zur Behandlung der Pankreatitis mit Glucagon. Fleischer, K., KaSPer, H. (Würzburg)

Gastrointestinale Blutungen bei Schlafmittelvergiftungen und cerebralen Komata. Brodersen, H. C., Baum, P., Meyer zum Büschenfelde, K. H. (Mainz) . . .

Untersuchungen zur Hemmung der stimulierten Magensekretion durch intraduodenale Applikation verschiedener Fettsäuren. Schmidt-Wilcke, H. A., Steinhagen, E., Steinhagen, P., Lapp, M. (Marburg) 


\section{Pulmonologie}

Zentrale Hämodynamik im Status asthmaticus. Wettengel, R., Böhnive, W., Hartmann, W., Sybrecht, G., Fabel, H. (Hannover)

Der Pulmonalarteriendruck bei obstruktiven Lungenerkrankungen vor und nach Gabe von Salbutamol. (H.hasis, R., Jescke, D., Schick, H.-D., Hilpert, P. (Tübingen)

Experimentelles Asthma bronchiale bei Hunden: funktionsanalytische und röntgenologische Untersuchungen. Kessler, G.-Fr., Gold, W. M. (San Francisco/Calif.) .

Elektrokardiographische Besonderheiten beim obstruktiven Syndrom. Esser, H., Fricke, G., Krkis, D., Simon, H. (Bonn) . . . . . . . . . . . . . . . . .

Objektivierung brocholytischer Therapie in der Praxis. Börngen, U. (Marburg) . .

Pharmakokinetische Untersuchungen am Menschen mit einem als Dosier-Aerosol verwendeten $\beta$-Sympathomimetikum. Seyberth, H. W., RAHN, K. H. (Aachen) .

Kombinierte Therapie mit Corticosteroiden und einem synthetischen Depot-ACTH bei chronisch obstruktiven Ventilationsstörungen. CEGLA, U. H., DemISCH, K. (Frankfurt/Main)

Zur atemdepressorischen Wirkung von Sauerstoff bei Patienten mit alveolärer Hypoventilation. NoLte, D. (Gießen)

Kurz- und Langzeitadaptationsmechanismen des kardiopulmonalen Systems nach Aderlaß bei Polyglobulien unterschiedlicher Ätiologie. RüHLE, K. H., KonıEtzko, N., Schlehe, H., Matthys, H. (Ulm) . . . . . . . . . . . . . . . . . . . Aussprache: Herr SchaRF, R. (Sulzbach/Saar) . . . . . . . . . . . . . . . .

Vergleichende Untersuchungen zum Gasaustausch der Lunge bei IPPV- und CPPVBeatmung und deren klinische Bedeutung. Schulz, V., Lmmbourg, P., Schrabel, K. H., Schmidt, W. (Mainz)

Die Diagnostik des beginnenden Asthma bronchiale. Gonsior, E., Thret, Cr., MererSydow, J. (Frankfurt/Main) . . . . . . . . . . . . . . . . . . . . . . .

Intra vitam-diagnostizierte diffuse Lungenamyloidose. Mall, W., Schwarz, J. A., SeEliger, H. (Homburg/Saar)

\section{Hepatologie}

Untersuchungen zur Induktion arzneimittelabbauender Enzyme bei chronischen Alkoholikern. Gundert-Remy, U., Marquardt, R., Andritsch, F., Weber, E. (Heidelberg-Weinsberg) . . . . . . . . . . . . . . . . . . . . . . . . . .

Beeinflussung der Aktivität mikrosomaler Enzyme in der Rattenleber durch Äthanol mit und ohne Arzneimittelgabe. Bode, Chr., Bode, J. Ch., Martint, G. A. (Marburg)

Glykogenolyse und Gluconeogenese der menschlichen Leber unter dem Einfluß von Äthanol. Dietze, G., Wrcklmayr, M., Grunst, J., Hepp, K. D., Braun, S., Mehnert, H. (München) . . . . . . . . . . . . . . . . . . . . . . . . .

Einfluß von Äthanol auf den Purinkatabolismus der menschlichen Leber. Grunst, J., Dietze, G., Wicklmayr, M., Mehnert, H., Hepp, K. D., Eisenburg, J. (München)

Beziehungen zwischen der Aktivität des arzneimittelabbauenden Enzymsystems in der Leber und dem Krankheitsverlauf bei experimentellem Leberkoma im "Tierversuch. Brachtel, D., Thimel, H., Zilly, W., Richter, E. (Würzburg) . . . . . . . .

Einfluß einer portocavalen Anastomose auf die Aktivität cytoplasmatischer, mitochondrialer und mikrosomaler Enzyme in der normalen und in der cirrhotischen Rattenleber. Bode, J. Ch., Bode, Cirr., Zelder, O., Mrddeler, A. (Marburg) . .

Cerebrale Aktivitätsänderungen bei gleichzeitiger Hyperammoniämie und Phenolämie. Elek trophysiologische Versuche an Katzen. Fischer, B., Reith, H.-J., Krauss, H., Fiene, R., Holm, E. (Heidelberg)

Experimentelle und klinische Untersuchungen über die Zunahme der $\gamma$-Glutamyltranspeptidaseaktivität im Serum bei hepatobiliären Erkrankungen. Thiele, K. G., Holmes, A. W., Matetenheimer, H. (Köln-Chicago) . . . . . . . . . . . . .

Über die primäre und sekundäre biochemische Antwort der Leber nach Gabe von DGalaktosamin beim Zustandekommen der Galaktosaminhepatitis. ReUT'TER, W., Bauer, Ch., Bachmant, W., Lesch, R. (Freiburg) . . . . . . . . . . . . . .

Beziehung zwischen Phsopholipoidzusammensetzung von Plasma und Lebermikrosomen bei tierexperimenteller Cholestase und Hepatitis. Gallenkamp, H., Brachtel, D., RICHTER, E. (Würzburg) 
Die Durchblutung der menschlichen Leber unter dem Einfluß pharmakologischer Dosen von Glucagon. Wicklmayr, M., Dietze, G., Czempiel, H., Hepp, K. D., Mennert, H., Henftling, H. G. (München) . . . . . . . . . . . . . . . .

Zur Pharmakokinetik von Chloramphenicol und Thiamphenicol bei gestörter Leberund Nierenfunktion. v. Oldeshausen, H.-F., Meur, H. P., Held, H., Hartmann, J., Berler, H. J. (Tübingen) . . . . . . . . . . . . . . . . . . . . . . .

Die Affinität von UDP-Glucuronyltransferase zu Chloramphenicol. Linhart, P. (Heidelberg

Digitalistoleranz bei Patienten mit akuter diffuser Leberzellschädigung. ZILLY, W., Dreykluft, M., Richter, E., Rietbrock, N. (Würzburg-Berlin). . . . . . . .

Aussprache: Herr Schneider, K. W. (Würzburg) . . . . . . . . . . . . . .

936

936

938

942

Uber die Pharmakokinetik des Azathioprins im Tierversuch und bei Patienten mit chronischen Lebererkrankungen. Bär, U., BeCker, H., MaY, B., MaY ER, D., OHLENDoRf, S., Otтo, P., Schmidt, F. W. (Hannover) . . . . . . . . . . . . . . .

Einfluß von Azathioprin auf Lebercirrhosen beim Menschen und im Tierexperiment. Perings, E., Brunner, G., Creutzfeldt, W. (Göttingen) . . . . . . . . . .

Bildung und Ausscheidung von Gallensäurensulfaten: Ein wichtiger Schutzmechanismus bei der Cholestase. Strehl, A. (Heidelberg) . . . . . . . . . . . .

Die qualitative und quantitative Gallensäurenanalyse im Urin als diagnostische Hilfe in der Differentialdiagnose des Ikterus. BACK, P. (Freiburg) . . . . . . . . . .

Gallensäurenuntersuchungen im Serum und Urin von Patienten mit dekompensierter Lebercirrhose. Wildgrube, H. J., Dittmann, K., ERB, W. (Frankfurt/Main) . .

Einfluß einer Phenobarbitalbehandlung auf die Gesamt- und Einzelgallensäuren im Serum und Leber von gesunden Ratten und Ratten mit einer ANIT-Cholestase. Leinweber, W., MühlenkaMr, H., Erb, W. (Frankfurt/Main)

Zur Bedeutung des enterohepatischen Kreislaufes für die Auswertung von Gallensaftanalysen zur Testung der Leberfunktion. Klapdor, R., Schliewe, J. (Hamburg)

Wie stark sind Patienten, Ärzte und Pflegepersonal im Operationssaal gesundheitlich durch halogenierte Inhalationsnarkotica gefährtdet? FREY, R., GosTOMzYK, J. G., Gregori, M., KapfHammer, H., SpierdiJk, J. (Leiden-Kaiserslautern) . . . . .

Echographische Diagnose und Differentialdiagnose diffuser Leberkrankheiten. Ansätze zu quantitativer Auswertung und Ergebnisse. RetrenMaIer, G. (Erlangen-Nürnberg) .

Rezidivierende Cholostase nach Ovulationshemmern bei primär sklerosierender Cholangitis. Hartmann, W., Goebell, H., Beneke, G., Rühle, K.-H. (Ulm) . . . .

Mathematisch-statistische Analyse laborchemischer Daten bei Cholestase. Linhart, P., Erbe, R., Kommerell, B., Papenberg, J. (Heidelberg). . . . . . . . . . . .

$\alpha_{1}$-Foetoprotein(AFP)-Nachweis in biologischen Flüssigkeiten bei primärem Leberzellcarcinom. GöTZ, H., BEGER, H. G. (Berlin) . . . . . . . . . . . . . . . .

Klinische und bioptische Befunde bei Australia-Antigen-positiven Blutspendern. Schlicht, I., Hasse, W., Alexander, M., Wersse, W., Sucker, U. (Berlin) . .

Verlaufskontrollen des Hepatitis B-Antigens während und nach akuter Virushepatitis in den Jahren 1964 bis 1972. Alexander, M., Scholz, V., Wenzel, H. (Berlin) .

\section{Kardiologie}

Zum Einfluß freier Fettsäuren auf elektrophysiologische Meßgrößen des Ventrikelmyokards. Lüderitz, B., Naumann D'AlnocovrT, C., Stalmann, R. (Göttingen) Aussprache: Herr Schneider, K. W. (Würzburg)

Experimentelle Untersuchungen zur Therapie infarktbedingter Arrhythmien mit Lidocain und Practolol. Stephan, K., Meesmann, W., Wild, U., Lattke, F., Bischoff, K. O. (Essen)

Die Beeinflussung der Flimmerschwelle des Herzens durch Practolol vor und nach akutem experimentellem Coronarverschluß. Schley, G., Meesmann, W., Wild, U., Wilde, A. (Essen)

Untersuchungen zur Veränderung der Exitabilität des menschlichen Herzens in der physiologischen Reizphase durch verschiedene Sympathicomimetika und Antiarrhythmika. Diewitz, M., Baldus, O., Siegert, H. (Köln) 
Die Wirkung von Antiarrhythmika auf die intrakardiale Erregungsleitung im HisBündelelektrogramm. SeIPel, L., GleichmanN, U., Loogen, F. (Düsseldorf) . .

Einige Grundlagen der klinischen Prüfung von Antiarrhythmika. Bleifeld, W., Merx, W., HaAger, E., Heinrich, D. (Aachen)

Wirkung eines Antiarrhythmikums auf die Häufigkeit von ventrikulären Extrasystolen und Salven. Bussmann, W.-D., Müller, E., Kaltenbach, M. (Frankfurt/Main)

Orale antiarrhythmische Langzeitbehandlung mit Aprindine (AC 1802) BreITHaRD'T, G., GleichmanN, U., Seipel, L. (Düsseldorf) . . . . . . . . . . . . . . . . Aussprache: Herr HILGer, H. H. (Köln) . . . . . . . . . . . . . . . . . .

Der Einfluß einiger coronarwirksamer Pharmaka auf Anginaschwelle, EKG-Reaktion und Myokardstoffwechsel während Frequenzbelastung bei Coronarkranken. Westermann, K. W., Kugler, G., Richter v. Arnauld, H. P., Rödiger, W. (Hamburg) . . . . . . . . . . . . . . . . . . . . . . . .

Vergleichende Untersuchungen über die Wirkung von Practolol, Pindolol und Propranolol auf die Hämodynamik und Contractilität des linken Ventrikels bei Patienten mit coronarer Herzerkrankung. Limbourg, P., Just, H., LANG, K. F. (Mainz)

Die Wirkung eines $\beta$-Receptorenblockers auf das Herzminutenvolumen - Untersuchungen bei essentieller Hypertonie und hyperkinetischem Herzsyndrom unter Berücksichtigung der Plasmaadrenalin- und -Noradrenalinspiegel. WALTER, I., Kusus, T., Wagner, K., Lydtin, H. (München).

Plasma- und Gewebskonzentration der Katecholamine und ihre Beeinflussung durch Antiarrhythmika. Brisse, B., Bräuer, B., Müller, W., Bender, F., (Münster) .

Atypische Dosis-Frequenzbeziehung als Besonderheit eines $\beta$-Receptorenblockers. Klempt, H.-W., Müller, W. D., Bender, F. (Münster) . . . . . . . . . . .

Wirkung von Propranolol auf die Mikrozirkulation bei Luft- und Sauerstoffmangelatmung. Sill, V., Siemssen, S., Kovalzick, E. (Hamburg) . . . . . . . . . .

Untersuchungen zum Mechanismus der Wirkung von Oxyfedrin (Ildamen) im Tierexperiment und am Menschen. Appex, E., Pflanz, G., Grobecker, H., Palm, D. (Frankfurt); Stratmann, D., Donike, M. (Köln)

Untersuchungen über den Myokardstoffwechsel des Meerschweinchens bei experimenteller Hyperthyreose. Rackwitz, R., Otter, H. P., JAHrmärker, H. (München) .

Untersuchungen über Verlauf und Bedeutung von Blutgaswerten, Lactat und Pyruvat bei Reanimation und Schock. JaHrmärker, H., Rackwitz, R., Theissen, K., Otter, H. P., Halbritter, R., Gallitz, T., Gross, W., Murr, H., Grohmann, H. (München) . . . . . . . . . . . . . . . . . . . . . . . .

Untersuchungen zur Frage der intestinalen Resorption von Sympathicomimetika beim Menschen. Petry, R., KolB, K.-H. (Hamburg-Berlin)

Folgen einer akuten bzw. chronischen Lymphstauung am Herzen und an der Aorta von Ratten nach experimenteller Blockade des Ductus thoracicus. Müller, N., Cremer, H., Louven, B. (Bonn)

Zur Pharmakokinetik von Digoxin, Acetyldigoxin und Methyldigoxin bei Gesunden und Kranken. Wildmeister, W., Strobach, H., Greff, K., Horster, F. A. (Düsseldorf) .

Untersuchungen zur Pharmakokinetik von Digoxin nach chronischer und akuter Verabreichung. Gilfrich, H. J., Bodem, G., Chidsey, C. A. (Denver/USA) . . . . .

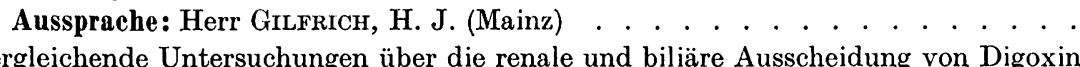
und $\beta$-Methyldigoxin beim Menschen. Köthe, E., Kramer, P., Scheler, F., (Göttingen) .

Aussprache: Herr ZıLly, W. (Würzburg) . . . . . . . . . . . . . . . . . .

Plasmaspiegel und Halbwertzeiten von Proscillaridin bei gesunden und niereninsuffizienten Versuchspersonen. Belz, G. G., BRECH, W., RUdofsky, G., HäRICH, B., Nissen, H., Franz, E., Strauch, M. (Ulm) . . . . . . . . . . . . . .

Speicherelektrolyte und Glykosidintoxikation. Bolte, H.-D., Buckesfeld, R., Lankisch, P. K., Larbia, D. (Göttingen) . . . . . . . . . . . . . . . . . Aussprache: Herr Schneider, K. W. (Würzburg) . . . . . . . . . . . . . .

Reaktivierung der Proscillaridin-gehemmten Membran-ATPase durch spezifische Antikörper: Enzymkinetische und immunochemische Untersuchungen. KLEEBERG, U. R., Belz, G. G., Brech, W., Rudofsky, G. (Ulm) . . . . . . . . . . . . . . Aussprache: Herr Schneid er, K. W. (Würzburg) . . . . . . . . . . . . . . 1052 
Weitere Untersuchungen zum Mechanismus der chronischen Natriumretention und Odembildung bei experimenteller Herzinsuffizienz. STUMPe, K. O., KRück, F., KleIN, H. (Homburg/Saar) . . . . . . . . . . . . . . . . . . . . . . . .

Aussprache: Herr Schnetder, K. W. (Würzburg) . . . . . . . . . . . . . . 1056

Hämodynamische Wirkungen von Pethidin am Patienten. Strauer, B. E. (Göttingen) 1056

Aussprache: Herr HILGer, H. H. (Köln) . . . . . . . . . . . . . . . . . . 1058

Herr Schneider, K. W. (Würzburg) . . . . . . . . . . . . . . 1059

Die Herzcycluszeiten und ihre Korrelation zu den Contractilitätsparametern. BischofF, K.-O., Meesmann, W., Wild, U., Stephan, K. (Essen) . . . . . . . . . . . . Aussprache: Herr Schneider, K. W. (Würzburg) . . . . . . . . . . . . . .

Optimaler Frequenzbereich bei Vorhofflimmern. Fricke, G., Simon, H., Pagenstecher, H., Kikis, D., Huszár, S. (Bonn) . . . . . . . . . . . . . . . . . . . . .

Av-Knotenermüdungszeit und vulnerable Zone des Vorhofs - elektrophysiologische Beobachtungen bei der Vorhofstimulation. Grohmans, H. W., Theissen, K., HalbRITTER, R., JAHRMäRKeR, H. (München) . . . . . . . . . . . . . . . . . .

Aussprache: Herr Schneider, K. W. (Würzburg) . . . . . . . . . . . . . .

Bestimmung des linksatrialen Druckes und des enddiastolischen Druckgradienten zwischen linkem Vorhof und linkem Ventrikel über die Q-I/IIA-OS-Formel aus dem Phonokardiogramm bei Mitralvitien. Jesse, R., Schnemder, K. W., Deeg, P. (Würzburg) .

Der Einfluß der Vorhofkontraktion auf den arteriellen Blutdruck bei Patienten mit Herzschrittmachern. BACHOUR, G., Bender, F. (Münster) . . . . . . . . . . Aussprache: Herr Schneider, K. W. (Würzburg) . . . . . . . . . . . . . .

Temporäre „Abschaltung“ implantierter Demand-Schrittmacher zur klinischen Diagnostik und Verlaufsbeobachtung. Schulten, H. K., Piehl, W., Röhrig, F. R., Baldus, O., v. Smekal, P. (Köln) . . . . . . . . . . . . . . . . .

Die Beeinflußbarkeit von Herzschrittmachern durch Radarstrahlung. RöHL, D., LAUN, H. M., Hauber, M. E. T., Volgt, H., Strauch, M. (Ulm) . . . . . . . . . .

Langzeitergebnisse bei Patienten mit implantierten elektrischen Herzschrittmachern. Nordeck, E., Knop, P., Stapenhorst, K., Riecker, G. (Göttingen) . . . . . . Aussprache: Herr SchneIder, K. W. (Würzburg) . . . . . . . . . . . . . .

Die Treffsicherheit der Computer-EKG-Auswertung. So, C. S., KolB, P., Blömer, H. (München)

Vergleich der EKG-Interpretation von sieben verschiedenen Computerprogrammen mit denen von drei Ärzten. Meyer, J., Merx, W., Heinrich, K. W., Effert, S. (Aachen)

Analyse von AV-Úberleitungsstörungen mit Hilfe des His-Bündel-EKGs unter besonderer Berücksichtigung von fasciculären Blockierungen. LANG, K. F., JUsT, H. G., Limboura, P., Fallen, H., Mathes, P. (Mainz)

Zur Diagnose und Differentialdiagnose des Rechtsschenkelblocks mit linkem posteriorem Astblock. Fleischmann, D., Bleifeld, W., Effert, S. (Aachen) . . . . . . .

Vergleichender Informationswert der Frankschen Ableitungen und der sog. bipolare. Brustwandableitung in der Hinterwandinfarktdiagnostik. Younossi, K., SchneIDER, K. W., RIEGER, H. (Würzburg) .

1059

1061

1061

1064

1068

1068

1071

1074

1074

1077

1079

1082

1083

1086

1091

1093

1097

Differentialdiagnosen bei Vorliegen eines ,,pathologischen" $Q$ in den rechtspräkordialen Brustwandableitungen des EKG. KLeY, H. K. (Düsseldorf); HarmJanz, D., Greven, G. (Hannover)

1100

Verhalten von ST-T-Vektor während des Belastungselektrokardiogramms in verschiedenen Ableitsystemen. Deeg, P., Jesse, R., Schneider, K. W., Younossi, K. (Würzburg) . . . . . . . . . . . . . . . . . . . . .

Zur Wertigkeit von Veränderungen im Belastungselektrokardiogramm bei Zustand nach Herzinfarkt. Becker, H.-J., SchäFer, G. E., HoffmanN, K. U., Kober, G., KaLtenbach, M. (Frankfurt/Main)

Klinische und elektrophysiologische Beobachtungen beim Syndrom der verlängerten QT-Dauer mit anfallsweisem Kammerflimmern (Jervell- und Lange-NielsenSyndrom). Theisen, K., Grohmann, H., Otter, H. P., Rackwitz, R., Halbritter, R., J AHRMÄRKER, H. (München).

Hämodynamische und angiokardiographische Befunde beim Jervell-Lange-NielsenSyndrom. Jehle, J., Schinz, A., RUdolPh, W. (München) . . . . . . . . . . 
Kinematographische Befunde nach Schuß- und Stichverletzungen des Herzens. Gradaus, D., Schmidt, E., Bachour, G., Bender, F. (Münster) . . . . . . .

Antikörper, antigene Determinanten und Kreuzreaktionsstudien bei Kardiomyopathien. Sack, W., Wachsmuth, E. D., Sebenina, H. (München-Basel)

Indirekter Immunfluorescenztest und indirekter Antiglobulinkonsumptionstest in der Diagnostik primärer Kardiomyopathien. OevermanN, W., Bolte, H.-D., ZwehL, W. (Göttingen)

Die Contractilität des linken Ventrikels beim Menschen unter isometrischer Belastung (Handgrip) und bei Vorhofstimulation. Mehmel, H. C., Krayenbühl, H. P., Amende, I., Wirz, P., Rutishauser, W. (Zürich)

Aussprache: Herr Schneider, K. W. (Würzburg)

Zur Frage des Energiestoffwechsels im hypoxischen Myokard. Kunn, H., Mertens, H. M., BreithardT, G., LoOgen, F., Kübler, W. (Düsseldorf) . . . . . . . . . .

Ventrikuläre Elastizität bei coronarer Herzerkrankung. MAthes, P., Just, H. (MünchenMainz)

Komplikationen der selektiven Coronarographie. KüblER, W., KREUzer, H., LoogeN, F. (Düsseldorf)

Aussprache: Herr HILGER, H. H. (Köln)

Die Wertigkeit der Myokarddurchblutungsmessung im Rahmen der Beurteilung von Patienten mit coronarer Herzerkrankung (KHE). SCHInz, A., JEHLE, J., RUDOLPH, W. (München)

Aussprache: Herr HILGER, H. H. (Köln)

1136

1138

Coronarreserve und myokardialer Sauerstoffverbrauch des linken Ventrikels bei Patienten mit stenosierender Coronarsklerose. Schenk, H., Strauer, B. E., Heiss, H. W., Kochsiek, K. (Göttingen)

Aussprache: Herr Hilger, H. H. (Köln)

Herr SchneIdeR, K. W. (Würzburg) . . . . . . . . . . . . . .

Die Dynamik des linken Herzens bei Ergometrie, Coronarographie und Ventrikelographie. Rödiger, W., Feige, A., Johannes, E., Polonius, M. (Hamburg) . . .

Zur Beziehung zwischen Coronargefäßveränderungen und Störungen der lokalen Myokardfunktion. Spiller, P., Schelbert, H. R., NeuHaus, K. L., Kredzer, H. (Düsseldorf)

1139

1142

1142

1143

1146

Quantitative Cinéangiokardiographie beim Normalen und bei Patienten mit Coronarsklerose (Three vessel disease). Schönbeck, M., Kray enbüHL, H. P., RUTishauser, W., Lichtlen, P., Wellauer, J. (Zürich)

Zur Form pathologischer Veränderungen der muskulären Herzwand bei coronarer Herzkrankheit. Lutz, E., Bartelt, K. M., Becker, H. J., Kober, G., Martin, K. L., Petersen, P., Kaltenbach, M. (Frankfurt/Main) . . . . . . . . . . .

Postmortale Enzymaktivitäten im menschlichen Herzmuskelgewebe bei coronarer Herzkrankheit. v. Smekal, P., Chriske, H. W., KüBler, W., Castrop, H. J., Schramm, G. (Köln-Düsseldorf)

Enzymuntersuchungen nach Polytrauma zur Differentialdiagnose der Herzkontusion. Louven, B., Schmidtmann, W., Straaten, H. G., Oest, S., Thelen, M., Cremer, H., Petersen, E. (Bonn) . . . . . . . . . . . . . . . . . . . . . . . Aussprache: Herr Schneider, K. W. (Würzburg) . . . . . . . . . . . . . .

Frequenzverhalten nach Herzinfarkt und nach Herzoperation in der Frühphase der Mobilisation. Simon, H., Huszár, S., Kikis, D., Fricke, G., Esser, H. (Bonn) .

Die klinische Wertigkeit der Pulmonalarteriendruckmessung bei der hämodynamischen Uberwachung des akuten Myokardinfarktes. Hanrath, P., Bleifeld, W., Mathey, D., Merx, W. (Aachen)

Häufigkeit der atrioventrikulären und ventrikulären Leitungsstörungen bei Kranken mit überstandenem Herzinfarkt und ihr Wert für die Langzeitprognose. OBERwitTLER, W. (Münster) . . . . . . . . . . . . . . . . . . . . Aussprache: Herr Holtmeine, H. J. (Stuttgart) . . . . . . . . . . . . . . .

Häufigkeit und Form von Arrhythmien im chronischen Verlauf des Herzinfarktes. Registrierung im Langzeit-EKG über 8 Std mit zwei bipolaren Ableitungen. ZrPFel, J., Just, H., Schmidt, W. (Mainz)

Die Beeinflussung der kardialen Leistungsbreite des Herz-Kreislaufgeschädigten durch regelmäßiges Ergometertraining in steigender Dosierung. Dikwitz, M., SCHweris, M., Scholz, W., Ellenried kR, W. (Bad Wiessee) 


\section{Diabetologie}

Untersuchungen zur Glykolyse und Gluconeogenese in der Rattenleber bei intra- und extrahepatischer Cholostase. Wolfert, W., Hartmarn, W. (Ulm) . . . . . . .

Uber den Effekt von 2-Deoxy-D-Glucose und Mannoheptulose auf die durch gastrointestinale Hormone induzierte Insulinsekretion. LuCke, C., Höffken, B., Mrtzkat, H. J., Trautschold, I. (Hannover)

Die Umwandlung von Proinsulin in Insulin und C-peptid in isolierten Langerhansschen Inseln der Ratte. Kemmler, W., Steiner, D. (München-Chicago) . . . . . . .

Steigerung der intestinalen Resorption von conjugierten Gallensäuren im Ileum diabetischer Ratten. Caspary, W. F., Creutzfeldt, W. (Göttingen) . . . . . . .

Untersuchungen zum Einfluß von Glucagon und Insulin auf die Glucoseresorption beim Menschen. Gottesbüren, H., Menge, H., Bloch, R., Lorenz-Meyer, H., Riecken, E. O. (Marburg)

Eine mögliche Rolle der Pankreashormone Insulin und Glucagon und des Entero. glucagons im postprandialen Fettstoffwechsel. BöTTGER, I., FALOONA, G. R., UNGER, R. H. (Dallas/Texas-München)

Ưber das Verhalten der Adenosinphosphate im Blut während mehrstündiger intravenöser Fructosezufuhr bei gesunden Menschen. Heuckenkamp, P.-U., ZöLlner, N. (München)

Klinische Untersuchungen zur Regulation des 2,3-Diphosphoglycerats in den Etythro. cyten von Diabetikern. Stande, E., Kolb, H., Mehnert, H. (München) . . . .

Die Glucoseproduktion der menschlichen Leber beim juvenilen Diabetes. HePp, K. D., Dietz, G., Wicklmayr, M., Mehnert, H. (München)

Übergewicht und Hyperinsulinismus als Folge qualitativer Ernährungsfaktoren. Laube, H., Raptis, S., Pfeiffer, E. F. (Ulm) . . . . . . . . . . . . . . .

Ausschüttung von peripher gespeichertem Insulin durch Muskelarbeit. BIRKNer, B., Dieterle, C., Erhardt, F., Gmeiner, K.-H., Henner, J., Wagner, R., Dieterle, P. (München)

Kompositionsänderungen der freien Fettsäuren unter oraler Glucosebelastung. Ravens, K. G., Basler, J., JipP, J. (Kiel)

Untersuchungen zur Wertigkeit verschiedener Glucosetoleranztests. Hausmans, L., Schubotz, R., Zöfel, P., Gassel, W.-D., Kaffarnik, H. (Marburg) . . . . . . Aussprache: Herr Hausmann, L. (Marburg) . . . . . . . . . . . . . . . . .

Herr Kaffarnik, H. (Marburg) . . . . . . . . . . . . . . . .

Radioimmunologische Bestimmung von Glibenclamid im Serum. GlogNer, P., BURmeister, P., Heni, N. (Freiburg) . . . . . . . . . . . . . . . . . . . . .

Dosisabhängigkeit der in der frühen Phase nach Sulfonylharnstoffgabe freigesetzten Insulinmenge. Dörfler, H., Marschall, M., Wolfram, G., Zöllner, N. (München)

Die kombinierte i.v. Glucose-Glibenclamidbelastung als Test zur Vorhersage des Erfolges der oralen Dauerbehandlung des Diabetes der Erwachsenen mit Glibenclamid. Raptis, S., Schröder, K. E., Pfeiffer, E. F. (Ulm) . . . . . . . . . . . .

Insulinsekretion nach kombinierter Gabe von Glucose und verschiedenen Sulfonylharnstoffen in äquipotenten Dosen bei Stoffwechselgesunden. HAPP, J., BEYER, J., Jungmane, E., Scherer, U., Haupt, E., Schöffling, K. (Frankfurt/Main) . . .

Untersuchungen zur Frage des Langzeiteffektes von blutzuckersenkenden Sulfonamiden auf Glucosetoleranz und Insulinsekretion bei erwachsenen Diabetikern. Hadpt, E., Cordes, U., Petzoldt, R., Beyer, J., Schöffling, K. (Frankfurt/Main)

Uber die Pharmakokinetik von Tolbutamid und Glykodiazin bei Leber- und Nierenschäden. Held, H., Eisert, R., Oldershausen, v., H. F. (Tübingen) . . . . .

Untersuchungen über die Bindung von Tolbutamid durch Cholestyramin in vitro und in vivo. Rosenstiel, K., Dördelmann, E., Berthold, K., Bock, K. D. (Essen) .

\section{Endokrinologie}

Klinische Ergebnisse mit einer radioimmunologischen Bestimmungsmethode für Trijodthyronin. HüFner, M., Hesch, R. D., z. Mühlen, V., EmRICH, D. (HeidelbergGöttingen)

$\mathrm{T}_{4}$-Bestimmung mit Hilfe des „Oxford $\mathrm{T}_{4}$-Säulentests“ und der Murphy-PatteeMethode. Ein methodischer Vergleich. DürR, H. K., Gerdes, H., JosePH, K. (Marburg) 
Auslösung einer Verbrauchscoagulopathie durch Colchicin-Verabreichung bei der Ratte. Obst, R., Müller-Berghaus, G. (Gießen) . . . . . . . . . . . . . .

Immunhämatologische und gerinnungsphysiologische Untersuchungen bei einem Autoimmunsyndrom mit autoimmunhämolytischer Anämie und Immuncoagulopathie. Kretschmer, V., Heene, D., Mueller-Eckardt, Ch., Heivrich, D. (Gießen) .

Erfolgreiche Spätthrombolyse einer Nierenvenenthrombose. Asbeck, F., Mies, R., KuxGreve, I., Wehrle, H.-J. (Köln) . . . . . . . . . . . . . . . . . . . . .

Untersuchungen zur Ätiologie der Faktor XIII-, Faktor V- und Fibrinogenmangels bei akuten Leukämien. Egbring, R., Schmidt, W., Havemann, K. (Marburg) . . .

Die Fibrinstabilisierung bei akuter Leukämie. Rasche, H., Dietrich, M., Gaus, W., SCHLEY ER, M. (Ulm) . . . . . . . . . . . . . . . . . . . . . Aussprache: Herr Wenzel, E. (Aachen) . . . . . . . . . . . . . . . . . .

Hämostasedefekte bei Plasmocytomkranken. Otт, V., KraUtheim, J. (Lübeck) . . Aussprache: Herr Holzhürer (Aachen) . . . . . . . . . . . . . . . . . .

Die gesteigerte Plättchenaggregation bei Diabetikern und ihre Bedeutung als Risikofaktor für Gefäßerkrankungen. JäGer, W., Pretsch, U., KRzywanek, H. J., BREDdIN, K. (Frankfurt/Main)

Einfluß der Insulintherapie auf die Blutgerinnung bei unkompliziertem Diabetes mellitus. Martin, W., Tilsner, V. (Hamburg-Eppendorf).

\section{Cytostaseologie}

Probleme der kombinierten Chemotherapie bei Neoplasien. Gerhartz, H. (Berlin) .

Kombinierte Chemotherapie maligner Tumoren. Weiss, D., Gerhartz, H., Paulisch, R., Schneider, H., Schöfer, P. (Berlin) . . . . . . . . . . . . . . . . .

Dosis - Wirkung - Relation von Endoxan. KuSAKabe, H. (Berlin) . . . . . . .

Die Kombinationschemotherapie des metastasierenden Mammacarcinoms nach Cooper. van Kaick, G., Drings, P., Fritsch, H., Moskwa, G. (Heidelberg) . . . . . .

Behandlung metastasierter solider Tumoren mit Cyclophosphamid, Methotrexat, Vincristin und 5-Fluoro-uracil. Fritsch, H., Castor, H., Drings, P., Moskwa, G. (Heidelberg)

Hodgkin-Sarkom bei immunsuppressiv behandeltem Erythematodes visceralis. ScHoLz, G., Rehn, K., Hunstein, W. (Heidelberg). . . . . . . . . . . . . . . . . . Aussprache: Herr Schilling, F. (Mainz) . . . . . . . . . . . . . . . . . .

Permanentkulturen lymphoblastärer Zellen als Modellsystem zur Untersuchung des Wirkungsmechanismus antileukämischer Substanzen. Wilms, K., Wilmanss, W. (Tübingen)

Triggerung von $\mathrm{G}_{0}$ - in Cycluszellen unter der Einwirkung cytotoxischer Substanzen. Müller, D., Wilmanns, W., Wilms, K., Hauber, J. (Tübingen)

Temperaturabhängige Veränderungen des Gehalts an ${ }^{3}$ H-TTP ${ }^{3}$ H-TDP und ${ }^{3}$ H-TMP im Walker 256-Carcinosarkom bei externem Angebot von ${ }^{3} \mathrm{H}$-Thymidin. Wüst, G., Buchholz, B., Witting, U., Norpoth, K. (Münster) . . . . . . . . . . . . .

Chromosomenveränderungen durch Cytostatika. Ruzicks, F., Nowo'rsy, H. (Wien)

Chromosomenveränderungen bei Mylerantherapie. Gebhardt, E., Schwanitz, G., HARTWICH, H. (Erlangen)

\section{Angiologie}

Untersuchungen zur Arbeitsdurchblutung in der Extremität unter der Wirkung eines $\beta$-Receptorenblockers (Practolol). Ca esar, K., Gräter, H., Knodel, W., EgGStein, M. (Köln-Tübingen)

Die Wirkung der a-Sympathicolyse beim Raynaud-Syndrom. Westermann, K. W., Langbehn, A., Fetge, A., Priester, G. (Hamburg) . . . . . . . . . . . . .

Verbesserung der Fließeigenschaften menschlichen Blutes durch subcutane Applikation von Arwin. Enrly, A. M., JUNG, H.-J. (Frankfurt) . . . . . . . . . . . . . .

Therapeutische Effekte auf den Stoffwechsel durch Verminderung der Blutviscosität (Defibrase). Köhler, M., Martin, M., Krüpe, M. (Köln) . . . . . . . . . . .

Quantitative Messungen der peripheren Durchblutung und weitere angiologische Aspekte bei Patienten mit Pseudoxanthoma elasticum. Nicolescu, R., Bork, K. (Mainz) 
Durchblutung von Hand und Unterarm bei Normotonikern und Hypertonikern. Merguet, P., Kapp, J. F., Anlauf, M., Bock, K. D. (Essen) . . . . . . . . .

Die Angiographie bei der Differenzierung der arteriellen Verschlußkrankheit vom peripheren Typ. Henninges, D., Zeitler, E. (Engelskirchen)

Die Blutdruckmessung in Fußrückenvenen unter Zehenstandbelastung bei Gesunden und Patienten mit Venenverschlüssen unterschiedlicher Lokalisation. MaRTIN, M. (Engelskirchen); VöLKER, D. (Bonn).

\section{Rheumatologie}

Querschnittslähmung und Vertebralarterieninsuffizienz infolge Halswirbelsäulenbefall bei chronischer Polyarthritis. Zeidler, H., Wittenborg, A., Vogelsang, H., WEIDNER, A. (Hannover).

Aussprache: Herr Schilling, F. (Mainz)

Erfahrungen mit der alternierenden Corticoidtherapie bei chronischer Polyarthritis. Wittenborg, A., Zeidler, H., Fricke, R., Geisthövel, W. (Hannover) . . . . Aussprache: Herr Schilling, F. (Mainz) .

Plasmacortisol tagesrhythmik nach intraartikulärer Injektion des Úberstandes oder des Gesamtinhaltes von Decortin-H-Kristallsuspensionen. Hartmann, F., Meissner, H. J. (Kiel) .

Die Streubreite der klinischen Gelenkuntersuchung, eine Voraussetzung für die Prüfung von Antirheumatika bei der chronischen Polyarthritis. Schaum, E., Brunotre, E., Herrlinger, J. D., Kriegel, W., Langness, U., Rave, G., Tolk, J. (Kiel) . . .

Die Wertigkeit serologischer Befunde (Influenza-KBR und Rheumaserologie) für die Diagnose der Myokarditis. Baldus, O., Piehl, W., Berendes, D., Chriske, H. W., Diewitz, M., Freyland, M. D., Hilger, H. H., Röhrig, F. R., Schulten, H. K., v. SMekal, P. (Köln)

\section{Infektionskrankheiten}

Untersuchungen über den Durchseuchungsgrad an Herpes simplex, Ornithose und Toxoplasmose bei der Berliner Bevölkerung. Alexander, N., Putzmann, L., Rühl, U., RumpF, S. (Berlin)

Influencaschutzimpfung: Antikörper gegen Hämagglutinin und Neuraminidase nach Applikation handelsüblicher $\mathrm{Al}_{2} \mathrm{O}_{3^{-}}$und $\mathrm{Al}(\mathrm{OH})_{3}$.Vaccinen beim Menschen. Kuwert, E., Schoop, H. J., Marcus, I. (Bochum).

Zum Problem der mikrobiellen Kontamination von Vena subclavia-Kathetern. Schwakzbeck, A., Wittenmeier, K. W., Twittenhoff, W. D., Strauch, M. (Mannheim-Heidelberg) .

Möglichkeiten der Antibioticatherapie durch Analysen mikrobiologischer Daten mittels elektronischer Datenverarbeitung (EDV). Iwand, A., ERBE, R., SplitThofe, R. D., Linhakt, P. (Heidelberg) . . . . . . . . . . . . . . . . . . . . . . . . .

Aktivitätsverluste von Antibiotica in Infusionslösungen. Lode, H., Küprer, G. (Berlin)

Zur neurotoxischen Wirkung der Penicilline. Weihrauch, T. R., Höffler, D., KrieglSTEIN, J. (Mainz)

\section{Psychosomatik und Medizinsoziologie}

Bedingungen und Möglichkeiten psychosomatischer Krankenbehandlung auf internistischen Stationen. KöHle, K., Schultheis, K. H., Simons, C., Scholrch, B. (UIm)

Psychosomatischer Konsiliardienst in der Inneren Medizin. - Ein Versuch, den Zusarnmenhang zwischen Individuum und Umwelt zu sehen. Schüffel, W., RotmanN, M., Schonecke, O. W., Herrmann, J. M. (Ulm) . . . . . . . . . . . . . . .

Freiheitsverlust als Krankheitsursache. Huebschmann, H. (Heidelberg) . . . . . .

Versuch einer Objektivierung des Aggressionsverhaltens psychosomatisch erkrankter Patienten. Freiwald, M., LiedtKe, R., ZepF, S. (Kiel)

Physiologische und psychologische Parameter bei Herzinfarktpatienten einer Langzeitstudie. StockmeIER, U. (Bernried) . . . . . . . . . . . . . . . . . 1454 


\section{Arbeitskreis Dokumentation und Statistik}

Der umstrittene Nutzen maschineller Befunddokumentation für die ärztliche Tätigkeit.

Proppe, A. (Kiel) . . . . . . . . . . . . . . . . . . . . . . . . . . . . 1461

Elektronische Informationsverarbeitung im klinischen Bereich. Ein praktischer Fortschritt oder ein wissenschaftliches Experiment? Reichertz, P. L. (Hannover) . 1464

Textkonserven zur Rationalisierung in Klinik und Praxis. Frank-Schmidt, H.-J. (Ludwigshafen-Oggersheim)

\section{Nachtrag zu den Verhandlungen 1972, 78. Band}

Synthesis of Lipid by Foam Cells in Atheroselerotic Lesions. DAY, A. J. (Melbourne, Australia) (Referat) . . . . . . . . . . . . . . . . . 1474

Namenverzeichnis ....................... 1476

Sachverzeichnis . . . . . . . . . . . . . . . . . . . . . 1483 
Londong, V., Blumberg, K., Erhardt, F., Müller, O. A., Pickardt, R. C., Scriba, P. C., von Werder, K., Dieterle, P. (3. Med. Abt. Städt. Krankenhaus München-Neuperlach u. II. Med. Klinik Univ. München): Hemmung der TsHSekretion durch Hypoglykämie*

Eine Hypoglykämie führt über die Reizung hypothalamischer Zentren zur hypophysären Sekretion von ACTH und Wachstumshormon. Die Mitteilungen über den Einfluß einer Blutzuckersenkung auf die hypothalamische-hypophysäre Regulation der Schilddrüsenhormonachse sind hingegen unterschiedlich [1, 2]. Wir untersuchten deshalb den Einfluß einer Insulinhypoglykämie auf das Verhalten von TSH und der peripheren Schilddrüsenhormone. Wenn eine Blutzuckersenkung über eine Stimulation des Hypothalamus zur Sekretion von TSH führt, wie dies Sendrail u. Mitarb. [2] aus ihren Untersuchungen postulierten, könnte man mit dem Insulinhypoglykämietest neben ACTH und Wachstumshormon eine weitere wichtige Hypophysenfunktion erfassen.

19 normgewichtige, schilddrüsengesunde Personen (13 Frauen und 6 Männer) erhielten am Morgen unter Grundumsatzbedingungen nach 14stündigem Fasten intravenös 0,15 bis $0,2 \mathrm{E}$ Altinsulin $/ \mathrm{kg}$ Körpergewicht. Vor und nach der Insulininjektion wurden in regelmäßigen Zeitabständen $(-15,0,15,30,45,60,90,180$, 240, $420 \mathrm{~min}$ ) Blutproben zur Bestimmung von Glucose, Cortisol [3], Wachstumshormon [4], $\mathrm{PB}^{127} \mathrm{~J}[5]$, des $\mathrm{T}_{3}$-in vitro-Tests [6] und der TSH-Spiegel [7] entnommen.

30 min nach der Insulininjektion fielen die Blutzuckerwerte von $89,6 \pm 8,1$ $\mathrm{mg}-\%(\overline{\mathrm{x}} \pm \mathrm{s})$ auf einen Tiefstwert von $40,15 \pm 9,8 \mathrm{mg}-\%$ ab. Als Ausdruck einer ausreichenden Blutzuckersenkung stiegen die Plasma-Cortisolwerte $(\mathrm{n}=16)$ von $15,3 \pm 5,1$ auf $34,8 \pm 8,2 \mu \mathrm{g} / \%(\overline{\mathrm{x}} \pm \mathrm{s})$ und die Wachstumshormonspiegel $(\mathrm{n}=8)$ von $1,1 \pm 1,3 \mathrm{ng} / \mathrm{ml}$ auf $43,3 \pm 24,9 \mathrm{ng} / \mathrm{ml}(\overline{\mathrm{x}} \pm \mathrm{s})$ an. Die Maxima für Cortisol und Wachstumshormon wurden jeweils $60 \mathrm{~min}$ nach der Insulininjektion erreicht.

* Mit Unterstützung der Deutschen Forschungsgemeinschaft und des SFB 51. 
In der Abb. 1 sind die Serumspiegel des $\mathrm{PB}^{127} \mathrm{~J}$ und des $\mathrm{T}_{3}$-in vitro-Tests bis 7 Std nach erfolgter Insulininjektion dargestellt. Während der gesamten Untersuchungsdauer kam es zu keiner signifikanten Änderung dieser beiden peripheren Schilddrüsenparameter. Auch der Index der freien Schilddrüsenhormone (Produkt

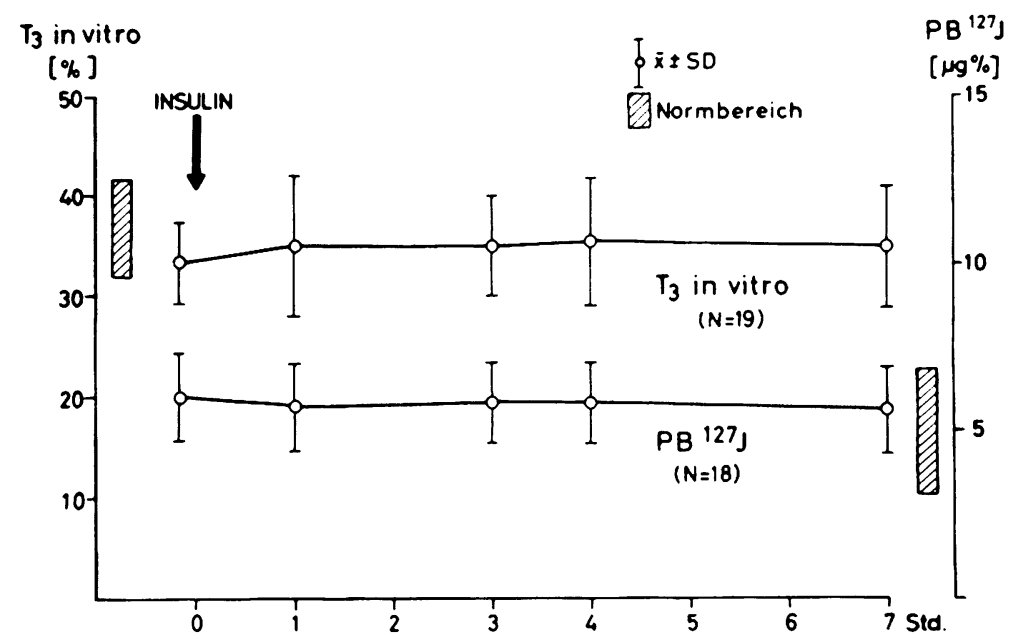

Abb. 1. Einfluß einer Insulinhypoglykämie auf das Verhalten des $\mathrm{PB}^{127} \mathrm{~J}$ (rechte Skala) und des $\mathrm{T}_{3}$-in vitro-Testes (linke Skala). Die schraffierten Säulen stellen die Normbereiche dar. Während der gesamten Untersuchungsdauer war eine signifikante Änderung nicht zu beobachten

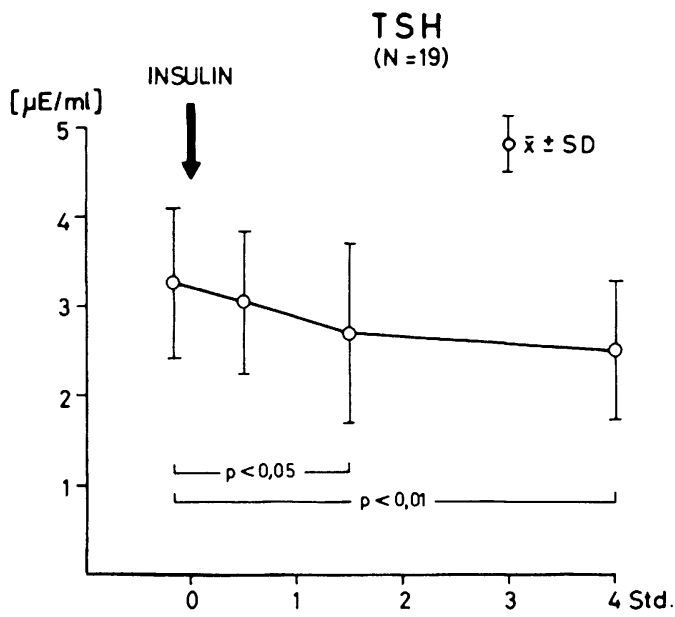

Abb. 2. Mittlere TS.H-Spiegel $(\overline{\mathrm{x}} \pm \mathrm{s})$ vor und bis zu 4 Std nach einer Insulinhypoglykämie. Der TSH-Abfall nach $90 \mathrm{~min}$ und nach 4 Std ist signifikant verschieden von den Ausgangswerten

aus $\mathrm{PB}^{127} \mathrm{~J}$ und sog. freiem $\mathrm{T}_{3}$ ) blieben entsprechend unverändert. Im Unterschied zu den unveränderten peripheren Schilddrüsenparametern kam es auf die Insulinhypoglykämie zu einem steten Abfall der TSH-Spiegel von 3,25 $\pm 0,85 \mu \mathrm{E}$ pro $\mathrm{ml}$ auf $2,69 \pm 1,01 \mu \mathrm{E} / \mathrm{ml}$ nach $90 \mathrm{~min}$ und auf $2,49 \pm 0,77 \mu \mathrm{E} / \mathrm{ml}$ nach 4 Std (Abb. 2). 
Dieser TSH-Abfall ist zwar geringfügig und es kommt ihm im Einzelfall keine diagnostische Bedeutung zu. Dennoch war der Abfall nach 90 min und nach 4 Std signifikant verschieden gegenüber dem Ausgangswert. Unseres Erachtens ist diesem zahlenmäßig wenig eindrucksvollen TSH-Abfall um so mehr Bedeutung beizumessen, als bei 15 euthyreoten Personen eine mittlere Spontanschwankung der TSH-Spiegel von nur $0,34 \mu \mathrm{E} / \mathrm{ml}$ über einen Zeitraum von $4 \mathrm{Std}$ gemessen wurde [8]. Außerdem fanden wir bei einer noch nicht abgeschlossenen Serie von subklinischen Hypothyreosen mit deutlich erhöhten basalen TSH-Spiegeln einen wesentlich stärker ausgeprägten Abfall von beispielsweise $33,4 \mu \mathrm{E} / \mathrm{ml}$ auf $24,7 \mu \mathrm{E}$ pro $\mathrm{ml} 4$ Std nach erfolgter Insulininjektion.

Unsere Ergebnisse stehen im Gegensatz zu den Befunden von Sendrail u. Mitarb. [2], die beim Menschen und beim Tier einen signifikanten Anstieg des $\mathrm{PB}^{127} \mathrm{~J}$ fanden, der nach Adrenalektomie geringer war und nach Hypophysektomie ausblieb. Blum u. Mitarb. [9] konnten, ähnlich wie wir, keine Änderung des $\mathrm{PB}^{127} \mathrm{~J}$ nach Insulinhypoglykämie beobachten. Dagegen beschrieben diese Autoren einen signifikanten Anstieg des Thyroxinjod und des freien Thyroxins, der zeitlich mit einem Abfall der TSH-Spiegel korrelierte.

Eine hypothalamisch-hypophysäre Stimulation der Schilddrüsenhormonachse durch eine Insulinhypoglykämie scheint nach unseren Befunden nicht wahrscheinlich. Durch die Blutzuckersenkung kommt es im Gegenteil zu einer signifikanten Hemmung der TSH-Sekretion, die nach vorläufigen Befunden bei primär erhöhten TSH-Spiegeln wesentlich ausgeprägter ist. Der TSH-Abfall könnte nach Blum u. Mitarb. [9] durch eine Feedback-Hemmung infolge erhöhter Thyroxinspiegel erklärt werden. Die erhöhten Thyroxinspiegel führen Blum u. Mitarb. auf eine Freisetzung aus der Leber zurück. Andererseits wäre aber der TSH-Abfall auch mit einer Hemmung der TSH-Sekretion durch die stress-bedingte Cortisolerhöhung zu erklären. Von einigen Autoren wird seit langem eine konkurrierende Wechselwirkung zwischen der Sekretion von ACTH und Wachstumshormon einerseits und von TSH andererseits angenommen. Eindeutige Beweise für eine derartige konkurrierende Wechselwirkung stehen unseres Erachtens aus. Es liegen jedoch vielfältige Befunde vor, daß die verschiedensten Stress-Situationen oder auch die Gabe von Corticoiden [10] eine Verminderung der TSH-Sekretion zur Folge haben. Infolgedessen wäre der von uns beobachtete Abfall der TSH-Sekretion auch durch den stress-bedingten Cortisolanstieg möglich.

\section{Zusammenfassung}

Bei 19 schilddrüsengesunden Personen wurde der Einfluß einer Insulinhypoglykämie auf das Verhalten des $\mathrm{PB}^{127} \mathrm{~J}$, des $\mathrm{T}_{3}$-in vitro-Tests und der TSH-Spiegel untersucht.

Das $\mathrm{PB}^{127} \mathrm{~J}$ und der $\mathrm{T}_{3}$-in vitro-Test blieben bis $7 \mathrm{Std}$ nach der Insulingabe unverändert.

Der TSH-Spiegel fiel von $3,25 \mu \mathrm{E} / \mathrm{ml}$ signifikant auf $2,49 \mu \mathrm{E} / \mathrm{ml} 4$ Std nach der Insulininjektion $\mathrm{ab}$.

\section{Literatur}

1. Odell, W. D., Wilber, J. F., Utiger, R. D.: Recent Progr. Horm. Res. 23, 47 (1967). 2. Sendrail, M., Bru, A., Blum, C.: Ann. Endocr. (Paris) 29, 681 (1968). - 3. Scriba, P. C., Gerb, A. C., Kluge, F., Boss, N., Müller, O. A.: Z. anal. Chem. 252, 284 (1970). - 4. Bottermann, P., Ermler, R., Henner, J.: Horm. Metab. Res. 3, 55 (1971). - 5. Horn, K., Scriba, P. C.: Dtsch. Ges. klin. Chem. 5, 3 (1970). - 6. Horn, K., Henner, J., Scriba, P. C.: Dtsch. Ges. klin. Chem. 2, 29 (1971). - 7. Erhardt, F., Grüner, J., Marschner, I., Pickardt, R. C., Scriba, P. C.: In Vorbereitung. - 8. Pickardt, R. C.: Habilitationsschrift, München 1972. 9. Blum, C., Cornette, C., Beckers, C.: Europ. J. clin. Invest. 3, 124 (1973). - 10. Wilber, J. F., Utiger, R. D.: J. clin. Invest. 48, 2096 (1969). 